Portland State University

PDXScholar

2016

Precipitation Intensity Required for Landslide Initiation in Rwanda

Angela N. Piller

Portland State University

Follow this and additional works at: https://pdxscholar.library.pdx.edu/honorstheses

Let us know how access to this document benefits you.

Recommended Citation

Piller, Angela N., "Precipitation Intensity Required for Landslide Initiation in Rwanda" (2016). University

Honors Theses. Paper 274.

https://doi.org/10.15760/honors.290

This Thesis is brought to you for free and open access. It has been accepted for inclusion in University Honors Theses by an authorized administrator of PDXScholar. Please contact us if we can make this document more accessible: pdxscholar@pdx.edu. 
Geology Honors Thesis

\title{
Precipitation Intensity Required for Landslide Initiation in Rwanda
}

Submitted to

\author{
Department of Geology, Portland State University
}

By

Angela N. Piller

June 10, 2016

\begin{abstract}
Rwanda has a high density of landslides, heavy precipitation events and a shortage of resources to study them, making it an excellent candidate for study using satellite-based remote sensing data. To assess landslide hazards countrywide, I first built a landslide inventory of 254 landslides and used a statistical methodology. Using logistic regression on 24 test variables, I determined that slope and population density are statistically most relevant to landslide occurrence in Rwanda. A preliminary predictive hazard map for Rwanda was produced, with an overall predictive accuracy of $79.6 \%$. Second, I worked to define a relationship between precipitation intensity and landslide density for a landslide-prone study area in western Rwanda. In the $1180 \mathrm{~km}^{2}$ study area, I mapped 577 landslides, using CNES/Astrium and WorldView satellite imagery in Google Earth over a study period of 2000 to 2015 . One $400 \mathrm{~km}^{2}$ part of the study area has a high landslide density of 1.4 landslides $/ \mathrm{km}^{2}$, while another $780 \mathrm{~km}^{2}$ part with identical geology, soils, land-use, and vegetation has a much lower landslide density. To identify possible triggering events for these landslides, I analyzed a 16 year record of TRMM (Tropical Rainfall Measuring Mission) satellite precipitation data. The high landslide density region and the low landslide density region were not notably different in rainfall, as quantified by recurrence interval analysis. A relationship between precipitation and landslide density could therefore not be developed, and the null hypothesis cannot be ruled out. This apparent lack of connection could result from a variety of factors including TRMM grid size, satellite imagery temporal resolution, antecedent soil moisture, or vegetation regrowth rates.
\end{abstract}

\section{Approval}

Dr. Adam Booth, Thesis Advisor

Date

Dr. Martin J. Streck, Department Chair

Date 


\section{Introduction}

Landslides in the United States cause more than $\$ 1$ billion in damages and 50 deaths per year (USGS 2014). Globally, figures are much more grave- between 2004 and 2010, 32,322 fatalities from landslides were recorded (Petley 2012). Monitoring, mapping and forecasting of these hazards are less than adequate in many parts of the world. In this study, "landslide" is a general term used for a variety of types of mass movement, including rock and soil falls, topples, slides, and flows. Landslides have a distinctive appearance when viewed from satellite or aerial photographs- the land is deformed and shows evidence of slippage. There is often a clear shape of a head scarp, hummocky slide, and a bulging toe (Ritter et al. 2011). Recent slides are visible as patches of bare earth, where land cover has been disrupted.

Landslide hazards lead to more economic losses and casualties than commonly recognized, due in part to casualties from slope failure being higher in developing nations (Guzetti et al. 1999). Research into rainfall induced landslides is often highly localized and relies on in situ rain gages. Methods based on high resolution spatial and temporal data and adequate ground data do not scale well to regional assessment (Kirschbaum 2009). Rapidly evaluating slope stability in response to storms, over a regional or larger scale is invaluable in a developing nation like Rwanda. Remotely sensed surface and atmospheric data provides an opportunity to assess landslide hazard at a regional scale (Kirschbaum 2012).

\subsection{Rwanda}

Rwanda is a $26,338 \mathrm{~km}^{2}$ country located in eastern Africa (Figure 1) with a population of approximately 11 million (CIA 2015, NISR 2014). This is the highest population density in mainland Africa (UNEP 2011). Seventy-five percent of the population of Rwanda earns a living from farming, mostly subsistence, and the landscape is ninety percent anthropogenic (eSoko 
2015). Rwanda has a nickname of "land of a thousand hills", and the country's steep slopes are prone to landslides (UNEP 2011).

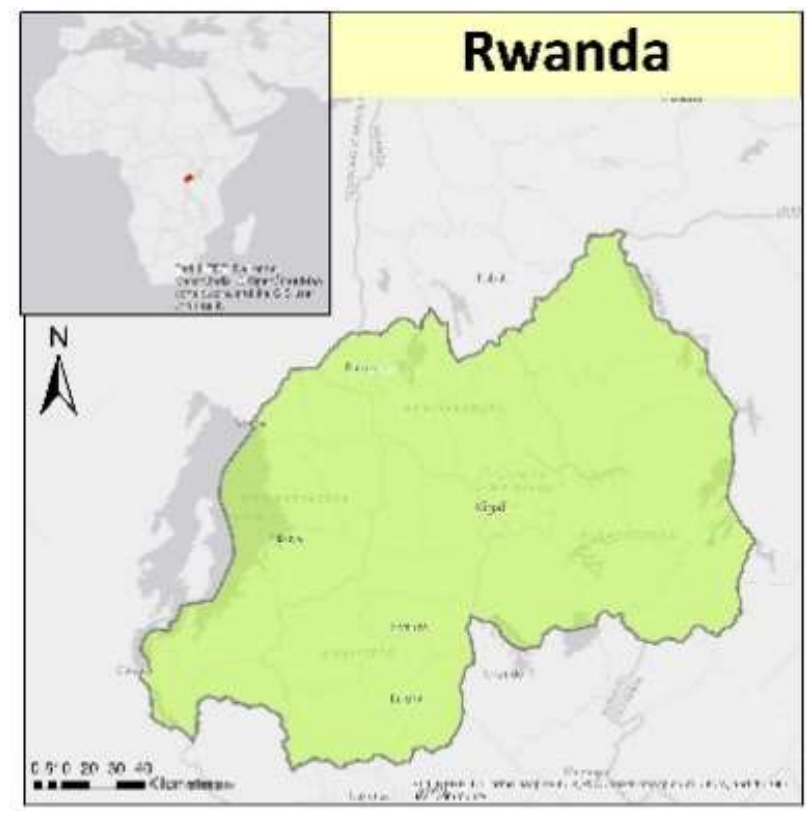

Figure 1. The country of Rwanda. Rwanda is $26,338 \mathrm{~km}^{2}$, about the size of the state of Vermont. It is located in Eastern Africa and has a population of approximately 11 million people

\subsection{Causes of landslides}

Material on a hillslope will remain stable as long as the shear stress does not exceed the shear strength of the slope materials (Ritter et al. 2011). When water fully saturates the soil, it pushes the sediment particles apart, which reduces the effective normal stress, and thereby decreases the frictional shear strength, leading to a possible failure surface (Terzaghi 1950). Studies have shown that an increase in pore pressure will initiate or increase the speed of a landslide, and a decrease in pore pressure will slow or stop a landslide (Iverson 2005). Even small differences in soil porosity influence landslide initiation and landslide rates (Iverson et al. 2000; Montgomery et al. 2002). Slope stability analysis is complex and involves many factors, but water plays a key role. 
In Rwanda, landslides are often associated with heavy precipitation events and flash floods. Conversely, landslides can cause flood events when the flow of a river is blocked temporarily by a landslide. When this natural dam collapses, large volumes of water can be released without warning, presenting a threat to settlements, people, and agriculture in the valleys (UNEP 2011).

\subsection{Precipitation}

In Rwanda there are two rainy seasons and two dry seasons: one long rainy season in February-May representing 48 percent of annual rainfall, one long dry season from June to midSeptember, a second rainy season in September-December representing 30 percent of annual rainfall, and a second short dry season in January-February, representing 22 percent of annual rainfall (UNEP 2011) (Figure 2). Rwanda receives an average of 1,200 mm of precipitation annually, but the annual average ranges from 2,000 $\mathrm{mm}$ in the west and north-western highlands to $600 \mathrm{~mm}$ in the eastern savannah (UNEP 2011). Available data suggests Rwanda experiences irregular and unpredictable rainfall patterns. Erratic rainfall data is observed in Kigali, one of the few locations where continuous rainfall data is measured. In seasons where excessive rainfall events are observed, they are not evenly spread throughout the season- instead, heavy rain typically falls in less than 3 days, sometimes over just one day (UNEP 2011). Landslides in Rwanda are often associated with heavy precipitation events and flash floods. 


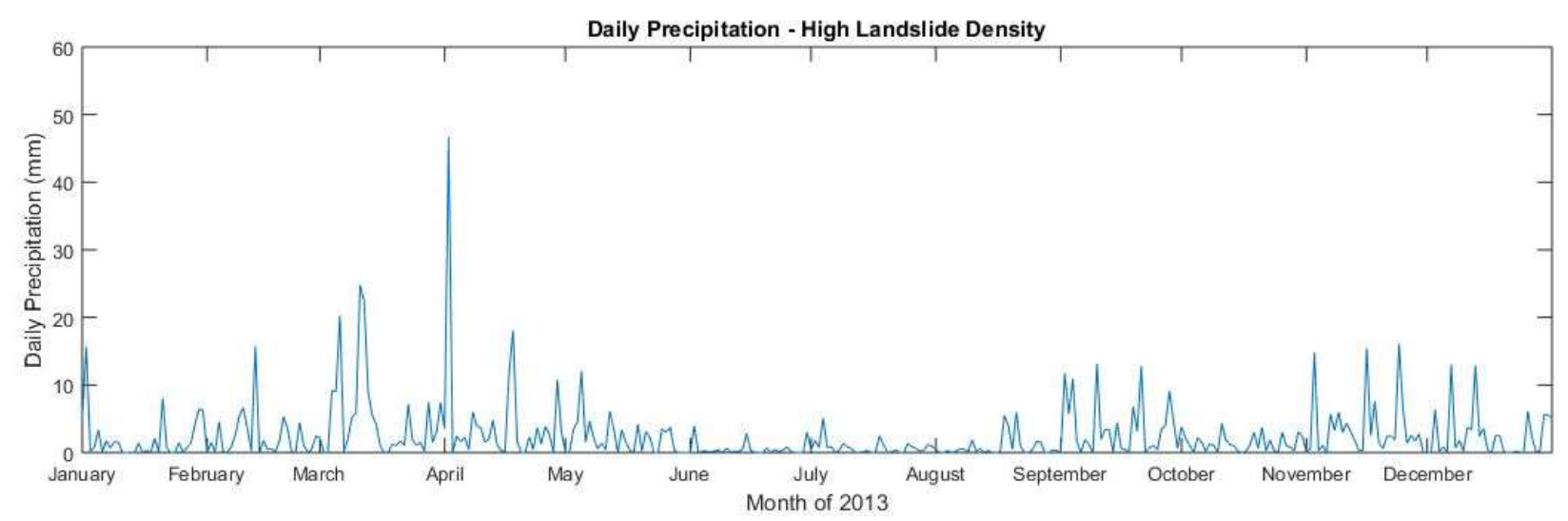

Figure 2. One year of TRMM data for Rwanda. This year shows the annual pattern of high rainfall in February through May, dry

in June to mid-September, briefly rainy again, then dry in January and February.

In the most thoroughly documented instance, extreme precipitation (over $140 \mathrm{~mm}$ in 3 days) in Ruhengeri prefecture resulted in catastrophic debris avalanches, torrents, and earthflows 24 hours later (Byers 1992). This study describes 3 days of heavy rain, a small (4.5 magnitude, located $150 \mathrm{~km}$ north in Uganda) earthquake, and then 24 hours later, on a day with low rainfall $(1.6 \mathrm{~mm})$, landsliding and debris flows began. The following day, there was heavy rain again, leading to continuing debris flows. It is possible that the earthquake had an adverse effect on slope stability, however, witnesses stated that the landslide activity actually began 24 hours after the small quake. Based on the available data, the landslide event appears to be directly related to soil moisture and infiltration capacity (Byers 1992).

\subsection{Storm Events}

Relative magnitude of a precipitation event can be quantified by calculating a recurrence interval. This is a statistical calculation of the probability that an event will be equaled or exceeded in any given year. For example, recurrence intervals are commonly used in flood hazard analysis in referring to a "100 year flood plain" or a "100-year storm". This means that there is a 1 in 100 chance that a "100-year storm" will be equaled or exceeded in any given year. 


\subsection{Determining Landslide Hazard}

There are many methods to assess landslide hazards, but van Westen et al. (2006), Dai et al. (2002) and others categorize these methods into four general approaches: inventory, heuristic, statistical, and deterministic. A landslide inventory is critical to investigations of where and when landslides have occurred (Kirschbaum et al. 2015). An inventory is often the first step for many of the other landslide susceptibility mapping methodologies (Dai et al. 2002). A heuristic approach uses expert opinions to estimate landslide hazard based on variables. This method may be remote, or based on direct, in-the-field observations (Metternicht et al. 2005). Weighting of variables may be subjective in this method (Dai et al. 2002). A statistical model generally takes the form of bivariate or multivariate statistical analyses of landscape characteristics that have been present in areas where landslides occurred (Metternicht et al. 2005). Statistical analysis estimates future landslide hazard for areas currently free of landslides but with similar conditions to areas with landslides (Dai et al. 2002). This method is used remotely, and requires the collection of large amounts of data. It is considered to be most suitable for landslide hazard prediction at a medium scale $(1: 25,000-1: 50,000)$ (Metternicht et al. 2005). A deterministic approach is based on slope stability analysis, and therefore is best used in small areas, when conditions are fairly uniform across the study area, and the landslide types are known and easy to analyze (Dai et al. 2002). These models often provide the most detailed results, but the data requirements can be prohibitive (Dai et al. 2002).

It is also important to differentiate between "risk" and "hazard". Varnes (1984) defines risk as "the expected number of lives lost, persons injured, damage to property and disruption of economic activity due to a particular damaging phenomenon for a given area and reference period". Risk is highly specific, and only practical to assess on a small scale. Hazard, one 
component of risk, is something to be determined on a larger scale (van Westen 2006).

Therefore, this study focused on identifying landslide hazard, not landslide risk.

The global landslide catalog, produced by Kirschbaum et al., (2015), only contains four landslides for the entire country of Rwanda, but a cursory review of Google Earth imagery shows that there are numerous undocumented landslides.

In this thesis I will lay out a methodology for determining study areas and building a landslide inventory. I will describe the statistical methods used to determine which variables are statistically most relevant to landslide hazard in Rwanda, and the satellite data products used for remote sensing. I provide a preliminary hazard map for landslides in Rwanda and an accuracy assessment. I will then investigate the relationship between precipitation and landslide initiation in a specific region of Rwanda with abundant recent landslides, and discuss the implications of my results.

\section{Study Areas}

\subsection{General Rwanda Landslide Study}

The Area of Interest (AOI) selected was the entire country of Rwanda, plus some of Southern Uganda, to capture landslides close to the border of both countries.

\subsection{Focused Landslide Study}

To isolate the effects of precipitation on landslides in Rwanda, this study looks at a smaller region of the country. I am looking at two defined locations, one with a high density of landslides, and one with a low density of landslides. Other factors that affect landsliding, such as slope, soil properties, bedrock geology, etc. are relatively constant across these two locations, but precipitation varies. This serves as a natural experiment, and I hypothesized that precipitation 
was the most important variable that could vary between the two sites. Focusing on a specific region of Rwanda allows for analysis of landslides and precipitation.

The first characteristic I used to identify potential study areas was a high density of landslides. Using the landslide inventory of Rwanda generated in the General Landslide Study, I identified several high density areas. Ideally the area would also have a minimum of two satellite images available within one year, to allow landslides to be dated to the nearest year.

Now that this general region was identified, the AOI needed to be limited to a geologic unit and a soil unit. The soil type and lithology for the majority of high landslide density areas were Umbric Acrisol and metasedimentary, respectively. I produced a map of all areas with this same soil and lithology type to identify an overlap (Figure 3). I further limited the location by considering land cover (Figure 4). The dominant land covers in the region of overlapping soil type and lithology are cropland, grassland, and forest, and I limited landslide mapping to cropland and grassland. Based on these criteria I selected a $400 \mathrm{~km}^{2}$ high landslide density study region, along with a $780 \mathrm{~km}^{2}$ (one TRMM grid square) low landslide density area (Figure 5). 


\section{Rwanda: Umbric Acrisol and Metasedimentary Lithology}

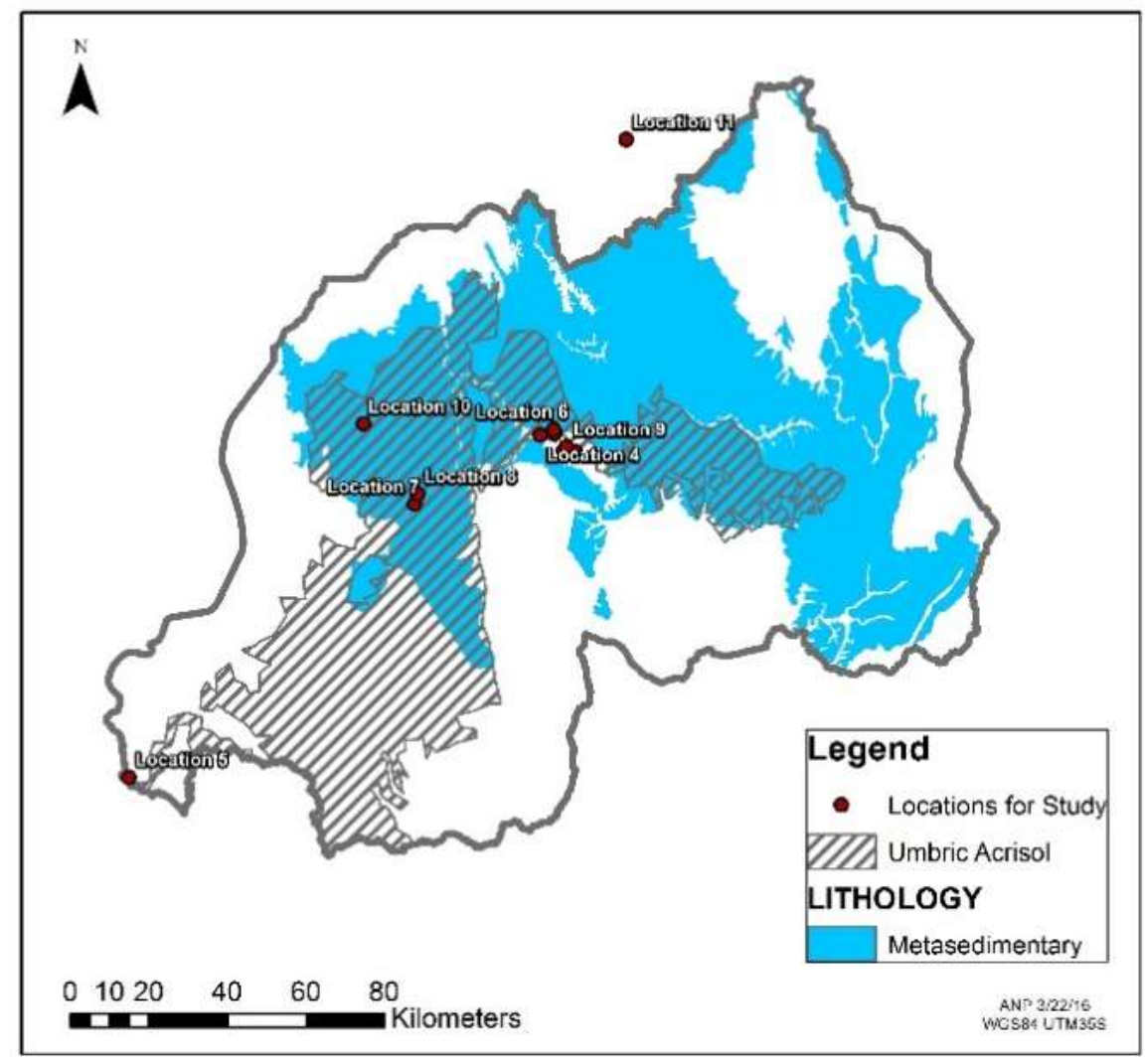

Figure 3. Map of Umbric Acrisol soils (gray striped area) and Metasedimentary lithology (blue shading) in Rwanda. Red points are areas of high landslide density identified in the General Rwanda Study. This figure demonstrates that most high density areas occur where this soil and lithology type coincide. 


\section{Rwanda: Landcover}

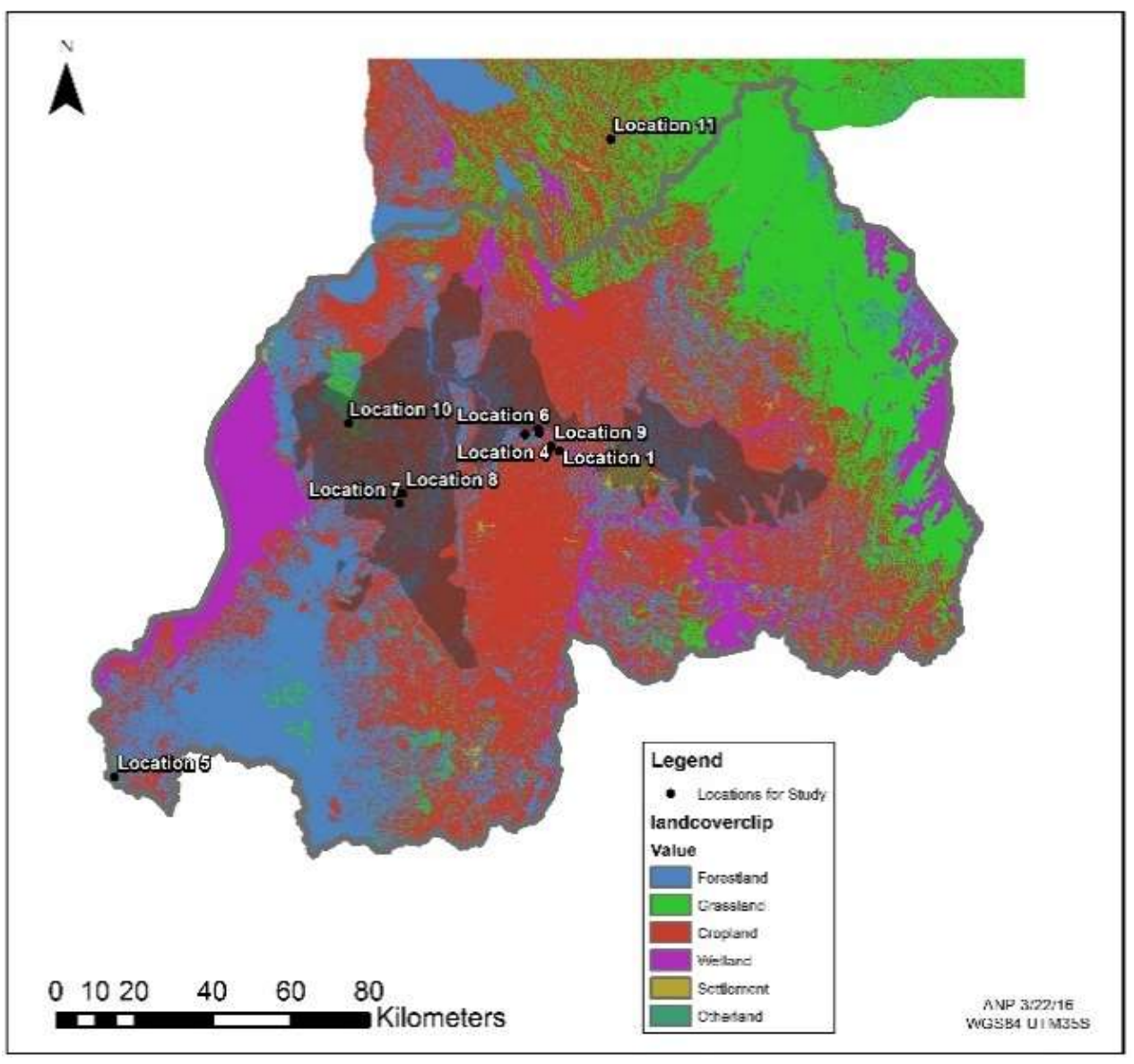

Figure 4. Map of landcover types in Rwanda. Points represent areas of high landslide density that are possible sites for study.

The gray shaded area represents all areas where Umbric Acrisol and metasedimentary lithology overlap (from Figure 3).

Landcover types found within this shaded area are grassland, cropland, and forestland. The high landslide density study area was selected from this image. 


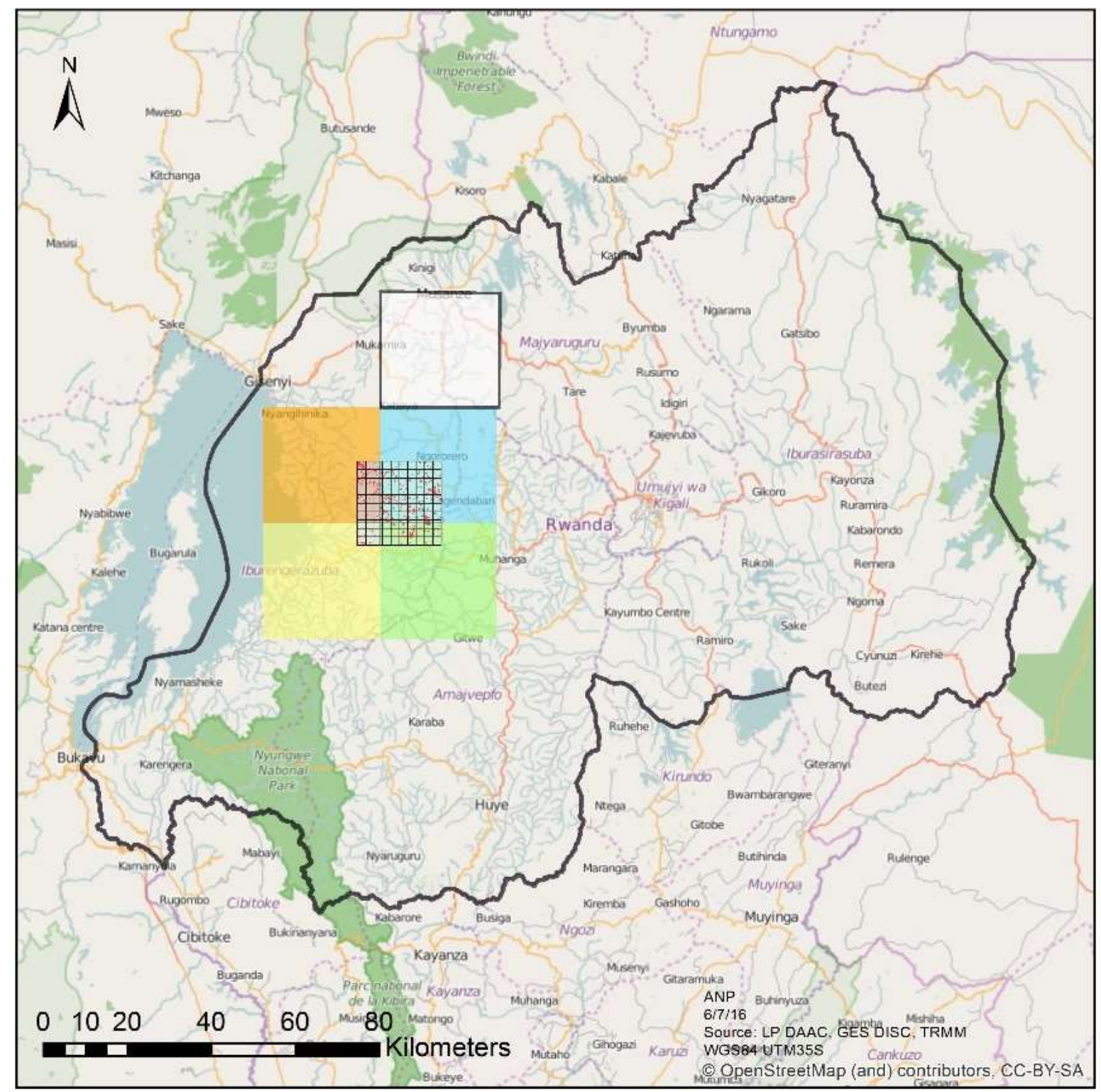

Figure 5. Overview map of the Focused Study area. Colored squares each represent a $0.25 \times 0.25$ degree TRMM pixel and the central gridded area shows the study area with landslide polygons in red. The black outlined box shows the low landslide density area.

\section{Methods}

\subsection{Remote Sensing Products}

Remote sensing data is invaluable in a developing nation that faces challenges in tracking, cataloging, and predicting the numerous landslides that occur each year. This is not unique to Rwanda- SERVIR (a joint development initiative of the National Aeronautics and 
Space Administration (NASA) and the United States Agency for International Development (USAID)) has completed a similar inventory and statistical analysis of landslides in El Salvador, as well as GIS (Global Information System) based hazard mapping in many other regions globally (SERVIR 2015). Remote sensing data makes it possible to study landslides in areas that are costly or otherwise inaccessible, as well as cover large areas.

\subsubsection{Tropical Rainfall Measuring Mission (TRMM)}

The remote sensing satellite TRMM launched in late November 1997, and gathered nearreal-time precipitation estimates until April 15, 2015 (GSFC 2016). This mission was flown by the National Aeronautics and Space Administration (NASA) and the Japan Aerospace Exploration Agency (JAXA) to improve our quantitative knowledge of the 3D distribution of precipitation in the tropics. The satellite had a passive microwave radiometer, a precipitation radar, and a visible-infrared scanner, among other instruments (GSFC 2016). The product used for this analysis is 3B42 V7 (Daily TRMM and Others Rainfall Estimate). This product has a daily temporal resolution, and is provided on a global $0.25^{\circ} \times 0.25^{\circ}$ grid over the latitude band $50^{\circ} \mathrm{N}-\mathrm{S}$ (GSFC 2016). Data is available from January 1, 1998 - May 2, 2015.

\subsubsection{Digital Elevation Model}

Digital elevation models (DEMs) used in this study are constructed using elevation data from stereo aerial photos, digitized contour maps, or global positioning systems (GPS). The NASA Shuttle Radar Topography Mission (SRTM) datasets result from a collaboration between NASA, the National Geospatial Intelligence Agency (NGA), and the German and Italian space agencies. The SRTM instrument was a specially modified radar system that gathered global elevation data over 11 days in 2000. The original SRTM DEM has a spatial resolution of 90 meters ( 3 arc second), and recently 30 meter ( 1 arc second) data has been made available 
(LPDAAC 2014). Datasets were generated from Shuttle Radar Topography Mission (SRTM) 1Arc second Digital Elevation Models (DEM). The source for the $90 \mathrm{~m}$ DEM is CGIAR, and the $30 \mathrm{~m}$ DEM was collected from LPDAAC.

\subsubsection{High-resolution satellite imagery}

Google Earth, as an aggregator of images, was the source for images used to build the landslide catalog for the General Study and the Focused Study. In the study areas, Google Earth provides CNES/Astrium and WorldView satellite imagery.

\subsection{Mapping}

When viewed from satellite images, landslides are visible as regions of bare earth with a rough and hummocky texture. As seen in Figure 6, the color usually contrasts with surrounding vegetation or cultivated land. The slide has a "natural" shape, as opposed to a more rectangular region of land cleared for farming or construction. Human intervention in mapping is important, otherwise farms, mining operations, and even flocks of sheep can be inadvertently identified as landslides.
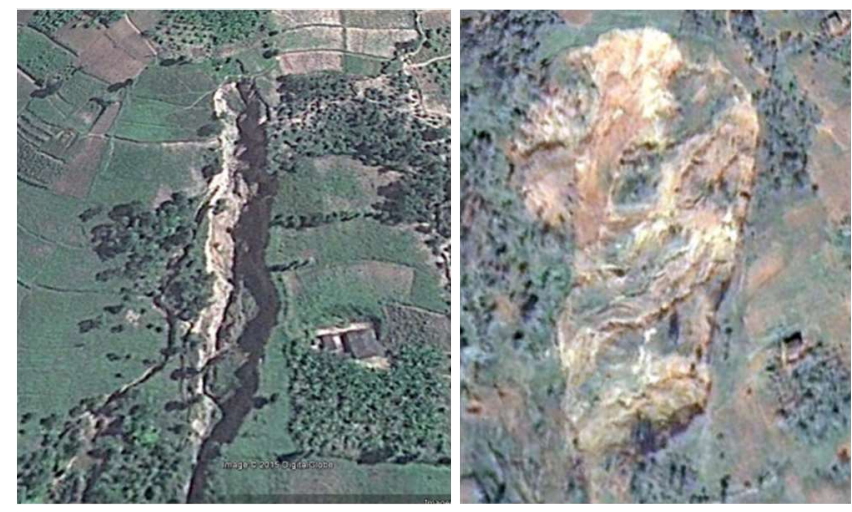

Figure 6. Examples of two recent landslides in the study area shown in WorldView/Google Earth satellite imagery. The color of the bare earth and the texture of the landslide scar stands out in contrast to the surrounding farmland or other ground cover. 


\subsubsection{General Study Mapping}

The first step in a statistical approach to estimating relative landslide hazard is gathering enough points representing landslide locations to produce a meaningful analysis. First, existing catalogs were consulted. Feldman and Byxbe (2014) produced a catalog for Rwanda and Uganda using an automated process to identify environmental and spectral characteristics indicative of landslides. Fifty-two points from this catalog were included in this study. The Global Landslide Catalog (GLC) was consulted next. The GLC methodology is to compile information from newspaper reports, published articles, aerial photographs, and other sources (Kirschbaum et al. 2015). The catalog contains 5741 points, but only 4 points in Rwanda. Additionally, GLC landslides can be cataloged as a point with a several kilometer radius of accuracy based on a news report rather than a visual sighting. Because of this methodology, these points were not usable in this study as they couldn't be matched to an exact point on a satellite image.

The inventory of landslides for Rwanda was built using visual interpretation of high resolution remote sensing images from 2000-2015. 2000 was chosen as the start year because at the time of this study, Google Earth contained no images for Rwanda before that date. As the spectral characteristics of landslides can be similar to other objects, like exposed rocks, roads, and settlements, a visual interpretation method is preferable to a fully automated information extraction method (Xu 2015). Of the 254 total points, the remaining 202 were selected this way (Ballard, 2015).

For logistic regression purposes (section 3.3.2) I generated not-landslide points within the AOI, semi-randomly. Based on the work of Dai et al. (2003) and Koutsias et al. (1998), the sampling size for this set was approximately the same as the landslide points set. I produced 
these points by importing the Google Earth kml file for the landslide inventory into ArcMap, building a $2 \mathrm{~km}$ buffer around each landslide point, and erasing study area contained in that buffer layer. Using the tool "Create Random Points" I created points over the remaining area of the AOI. These points then had to be imported into Google Earth and visually inspected; I discarded any points located within landslides, bodies of water, and cloudy or otherwise obscured areas. The first 253 of the remaining not-landslide points were retained.

\subsubsection{Focused Study Mapping}

For this study, I mapped all landslides that could be recognized at an eye altitude of approximately 1830 meters from the currently available satellite images, starting from my existing landslide inventory of Rwanda and adding additional points by locating patches of exposed soil in landslide scars and runout tracks (Figure 6). Similar to the General Study (Section 3.2.1) I built this inventory using visual interpretation of high resolution remote sensing images. To ensure no regions of the study area were overlooked, I used a grid overlay on the study area. I outlined each landslide with a polygon so that the area could be calculated (Figure 7) (see section 4.2 below). 


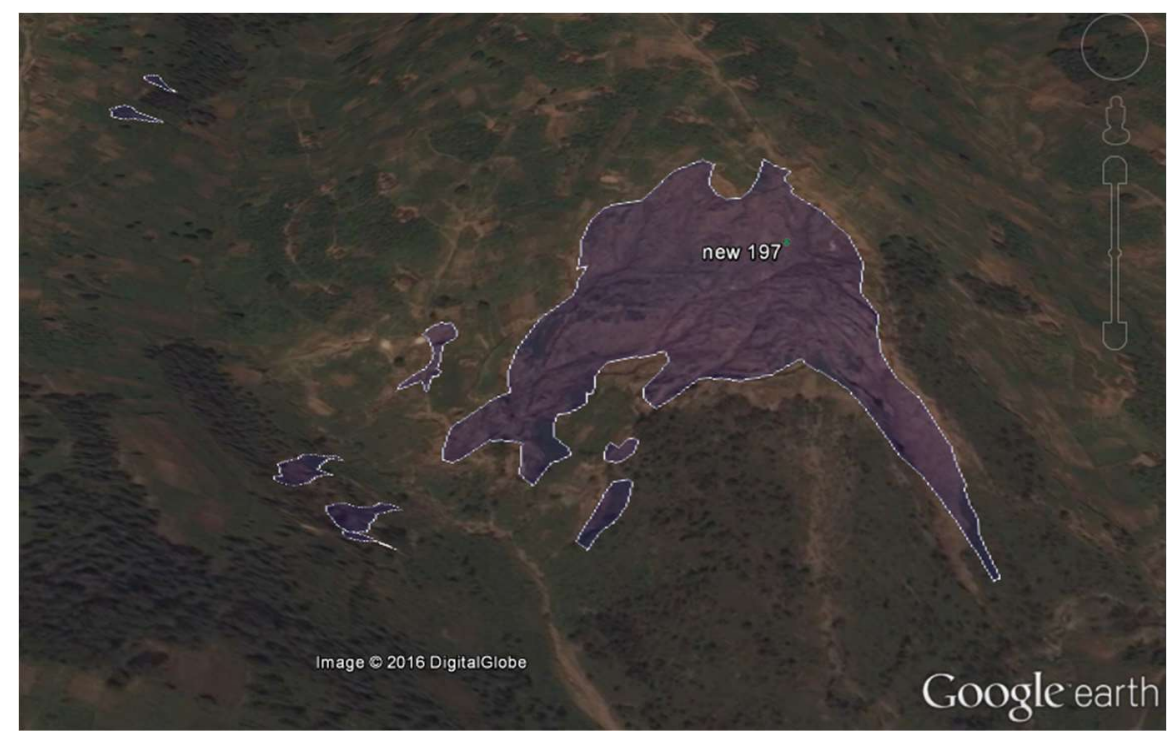

Figure 7. Example of polygons marking landslides in Google Earth. Each area identified as a landslide scar is outlined with a polygon to approximate the shape and area covered by the slide. Largest landslide is about 181 meters across, and 170 meters top to bottom

\subsection{Analysis}

\subsubsection{General Study}

I completed a general study of landslide hazards in Rwanda in August 2015, with the assistance of SERVIR, a joint development initiative of the National Aeronautics and Space Administration (NASA) and the United States Agency for International Development (USAID). This study focused on the development of a landslide inventory and a statistical methodology for assessing landslide hazards. Using logistic regression on 23 test variables (Table 1) and a sample of over 254 landslides, I determined which variables were statistically most relevant to landslide occurrence in Rwanda.

I derived thirteen of the variables from SRTM (Shuttle Radar Topography Missiongenerated DEMs (Digital Elevation Models) and tested them at both 30 meter and 90-meter resolution. The source for the 90 meter DEM is CGIAR, and the 30 meter DEM was collected from LPDAAC. As most previous research would have been completed with a 90 meter DEM, 
both 30 meter and 90 meter were used in this study to see if 30 meter data universally provided a superior regression result. Potentially influential variable ideas were drawn from the literature review, including Dai and Lee (2002), Dai et al. (2002), van Westen (2006), and Anderson (2012). All datasets were projected to WGS84 UTM35S.

The remaining 10 variables were collected from sources such as the Regional Centre for Mapping of Resources for Development (RCMRD), Climate Hazards Group InfraRed Precipitation with Station data (CHIRPS), the Consultative Group for International Agricultural Research (CGIAR), and the Rwandan government. All datasets were projected to WGS84 UTM35S (Ballard 2015).

\subsubsection{Logistic regression}

Logistic regression is useful for finding the relationship between a list of independent variables and a binary dependent variable (Dai and Lee 2002). In this case the dependent variable is presence of a landslide $(0=$ no, $1=$ yes $)$ and the independent variables are the variables selected and researched for each landslide point (Table 1). A Logistic Regression method pairs well with a geospatial (GIS) methodology. A statistical method, combined with landslide inventory maps, may provide the best risk assessment for the available input data over larger areas (van Westen 2006).

The logistic regression test will show which variable is the most significant for predicting landslides in Rwanda. A statistical approach is based on the assumption that landslides are likely to occur under the same conditions as those which the occurred in the recent past (vanWesten et al. 2006).

The general form of a logistic regression equation is

$$
Y=A x_{1}+B x_{2}+C x_{3}+\cdots Z x_{n},
$$


where $\mathrm{x}_{1}, \mathrm{x}_{2}, \mathrm{x}_{3}, \ldots \mathrm{x}_{\mathrm{n}}$ are the collected variable values for each landslide, and $\mathrm{A}, \mathrm{B}, \mathrm{C} \ldots \mathrm{Z}$ are the coefficients calculated for all landslide points.

Table 1. Twenty-Three variables used for Logistic Regression.

\begin{tabular}{|l|l|}
\hline 30 year rainfall & Land Cover \\
\hline Aspect* & Lithology \\
\hline Curvature(overall)* & Population Density \\
\hline Curvature (plan)* & Slope* \\
\hline Curvature(profile)* & Soil Moisture \\
\hline Distance from Populated Area & Soil Type \\
\hline Distance to Fault & Sediment Power Index* \\
\hline Distance to Road & Sediment Transport Index* \\
\hline Drainage Density* & Surface Roughness* \\
\hline Earthquake Hazard (PGA) & Topographic Wetness Inde** \\
\hline Elevation* & Vertical Distance to Drainage* \\
\hline Horizontal Distance to Drainage* & \\
\hline
\end{tabular}

Note: Thirteen variables with * are SRTM DEM derived and were tested at both 30 meter and 90 meter resolution.

I collected values for each variable for each landslide point using Multi Values to Points and Spatial Join tools in ArcMap. Values were compiled in Excel, then imported into the statistics program for logistic regression testing.

The logistic regression calculations were produced using the statistics program MYSTAT, a student version of SYSTAT. This program was chosen for its graphical user interface and low cost (free). First, a correlation check is performed. A "Pearson's product moment correlation coefficient" method was used. Correlation is calculated by dividing the covariance of two variables by the product of their standard deviations (SYSTAT 2007). Any variables with correlations of 0.5 or higher are not run in combination with each other. 
Using MYSTAT, I tested all variables, one at a time. A binary dependent variable called "Landslide", with a value of 0 for no landslide and 1 for yes, landslide, was tested along with a constant and each of the 23 independent variables. This compares the performance, and informs future decisions of which variables to pair. Next, variables are run in pairs of two. Again, a binary dependent variable is set equal to the constant and independent variables, and coefficients are calculated. The metrics I used to measure statistical significance are Akaike Information Criterion (AIC), p-value, McFadden's Rho-squared, and Area under the Receiver Operating Characteristic (ROC Curve). McFadden's Rho-squared was used as the main indicator of quality, and remaining metrics were used to break any "ties".

The coefficients for the variables with the best statistical significance were inserted into Equation 1 to produce the model for landslide hazard. Coefficients represent the change in logit of each unit change in predictor (SYSTAT 2007).

I produced a hazard map using the coefficients for the variables selected from the Logistic Regression. The layers for the variables selected as “best” (highest McFadden's Rhosquared) were opened in ArcMap, and converted to raster files. I used the tool "Raster Calculator" to build a new layer using the model found in the logistic regression. In order to create a map with values for each pixel ranging from 0 to 1 , the values must be normalized, using the equation

$$
\frac{e^{[\text {logistic regression model }]}}{1+e^{[\text {logistic regression model }]}}
$$

This transformation is more thoroughly described by Peng et al (2002) in Anderson (2012). A pixel value of 0 means low hazard, and 1 means very high hazard. "Low" "Medium" and "High" categories were assigned evenly to resulting values. 


\subsubsection{Accuracy Test}

A logistic regression model is of little use without a metric for its accuracy. To this end, thirty percent of all points, landslide and not-landslide, were selected randomly and withheld from the logistic regression tests. This set is the "reference set". These points were not used in the logistic regression test; instead I used them to assess the accuracy of the model built using the remaining $70 \%$ - the "response set". The 152 points in the reference set and the hazard map were opened in ArcMap, and the "Extract Values to Points" tool was used to check the calculated hazard value for each point. Values of 0.5 and greater were considered to be landslides, and values less than 0.5 were considered to be non-landslides.

\subsubsection{Focused Landslide Study}

I downloaded TRMM precipitation data from REVERB for all dates available (1/1/1998$5 / 2 / 2015)$. TRMM data is provided as binary files containing data from $50 \mathrm{~N}$ to $50 \mathrm{~S}$ latitude. I developed a MATLAB script to interpret the TRMM files and pull out specifically the data for my study area (Appendix). Since the high landslide density area spans 4 different TRMM grid squares, I pulled data for each pixel and combined it using a weighted average (Figure 5). I designed the script to combine the thousands of individual daily files into one array, calculated the recurrence interval and exceedance probability of storms with a given total precipitation amount, and generated time series and recurrence interval plots.

To produce a recurrence interval, each precipitation value must be given a rank, in order from largest to smallest. If $\mathrm{n}$ represents the number of measurements, the formula is

$$
\text { recurrance interval }=100 * \frac{r a n k}{n+1} .
$$

The formula for exceedance probability is

$$
\text { exceedance probability }=\frac{n+1}{\text { rank }} \text {. }
$$


The nearby TRMM grid square with a low density of landslides, but otherwise similar to the main study area was identified for comparison. I ran the script to generate time series and storm recurrence interval plots for this region as well. ArcGIS was used to calculate area of each slide, and total landslide density for the study area.

\section{Results and Discussion}

\subsection{General Study Results}

The pair of variables that significantly predicted locations of slope failures was slope (calculated with a 30-meter resolution SRTM DEM) and population density (2002). In general, the 30 meter DEM variables consistently performed better than the 90 meter DEM variables. The slope and population density pair have a McFadden's $\mathrm{R}^{2}$ of 0.388 . McFadden's $\mathrm{R}^{2}$ ranges from 0 to 1 , with a higher value indicating more significant results. A McFadden's $\mathrm{R}^{2}$ value between 0.2 and 0.4 is very satisfactory (SYSTAT 2007). The logistic regression equation found for these two variables was

$$
Y=-4.639061+(10.030704 * \text { Slope } 30)+(0.003977 * \text { PopDen }) .
$$

I used the "reference set" of points to assess the accuracy of the model built using the "response set". There were more false positives than false negatives, which means most error is on the side of over-predicting landslides. The overall accuracy, determined by cross-validation, was $79.6 \%$ (Table 2). 


\begin{tabular}{|c|c|c|c|c|c|}
\hline & & \multicolumn{2}{|c|}{ Predicted } & \multirow[t]{2}{*}{ Total } & \multirow[t]{2}{*}{$\begin{array}{l}\text { Correctly } \\
\text { Classified }\end{array}$} \\
\hline & & Yes & No & & \\
\hline \multirow{2}{*}{ Observed } & Yes & 67 & 12 & 79 & $84.8 \%$ \\
\hline & No & 19 & 54 & 73 & $74.0 \%$ \\
\hline Total & & 86 & 66 & 152 & \\
\hline Overall & & & & & $79.6 \%$ \\
\hline
\end{tabular}

Table 2. Accuracy assessment for hazard map built using slope and population density (Piller 2015). Values in table are the total number of landslides in each category.

I produced a preliminary predictive hazard map for Rwanda using equation (5) (Figure 8). Although population is represented in the hazard map, this does not become an assessment of risk to population or property. Population density is included in the map because it was a significant result in the logistic regression, which suggests that some aspect of human presence is related to landslide occurrence in Rwanda. The map shows a high hazard in the area surrounding Kigali, which is the area that has the highest population density in Rwanda. The western part of the country that shows a high hazard is near the Albertine rift of the Great Rift Valley. 


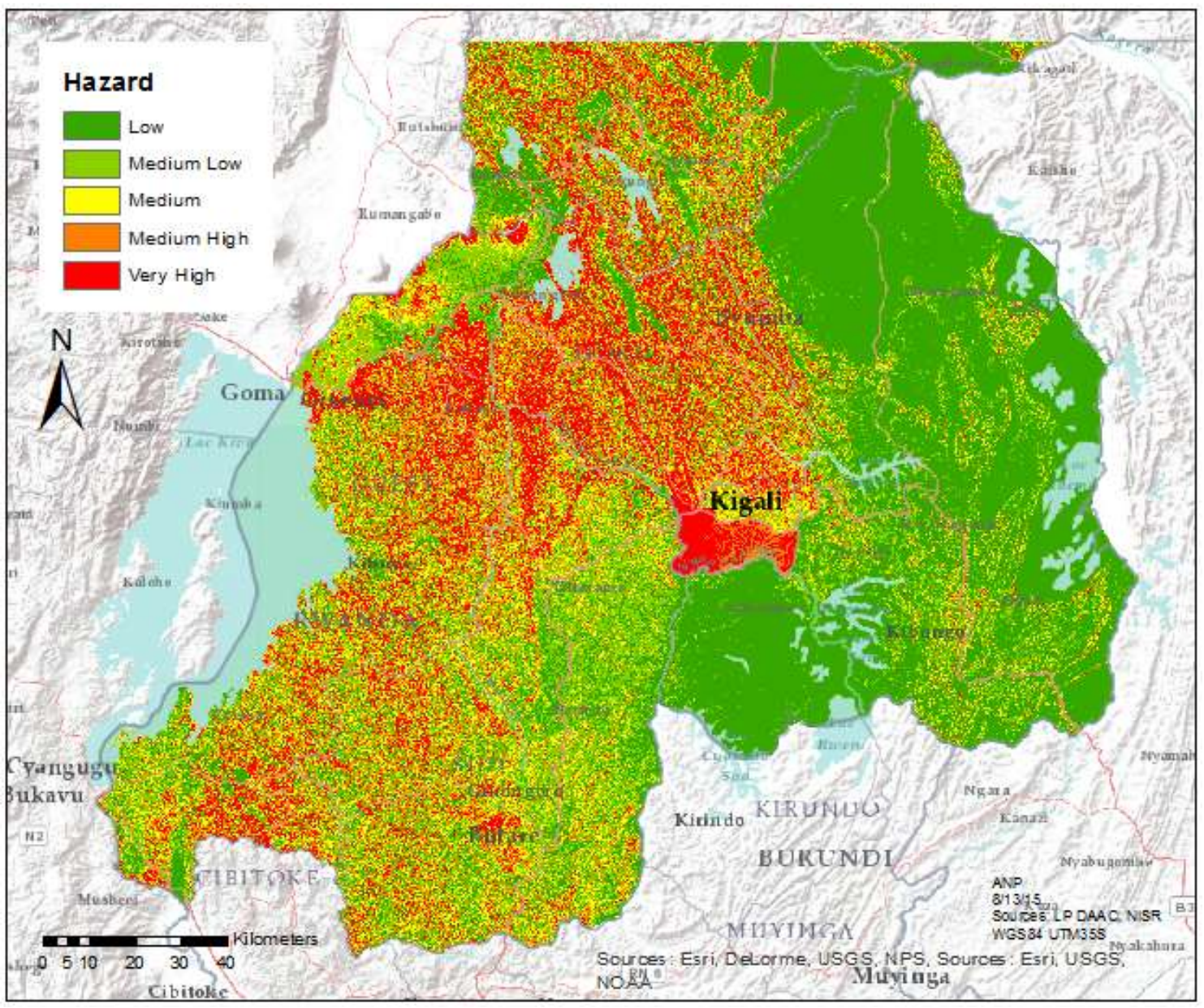

Figure 8. Landslide Hazard Map for Rwanda, based on slope and population density (Piller 2015).

\subsubsection{General Study Discussion}

This hazard map, in the context of Rwanda's topography, seems reasonable. The areas marked as a very high hazard are in fact on steep hillsides or mountain tops. The larger green areas are flat plateaus. With a flat enough slope, sediment transport is minimal and can't really be considered a "landslide". It is not unexpected that slope would be found as a crucial variable in landslide prediction.

Human impact is significant, and also not entirely unexpected, as $90 \%$ of the country's landscape is anthropogenic. Much of this is farming, but small-scale mining is also impacting the environment through river bank ripping and landslides (Dusková 2014). 
One large high hazard area is found in the area of Kigali, the capital city of Rwanda. The city has a high population, and it is difficult to observe landslides as they are quickly cleaned up, but large numbers of landslides are reported in this area, so it is reasonable to see this area marked as a high hazard.

There is a difference in data granularity between the two variables used to produce this hazard map (Figure 9). Population density was calculated per district, a relatively large political unit. Data is available to calculate this variable by smaller units, called cells, but it is unclear if this would lead to any change in accuracy of the hazard map without analyzing the calculated coefficients provided by the logistic regression tests. Slope is at a 30 meter resolution, which is still much higher than population density, but using population cells will improve the overall granularity of the hazard map.
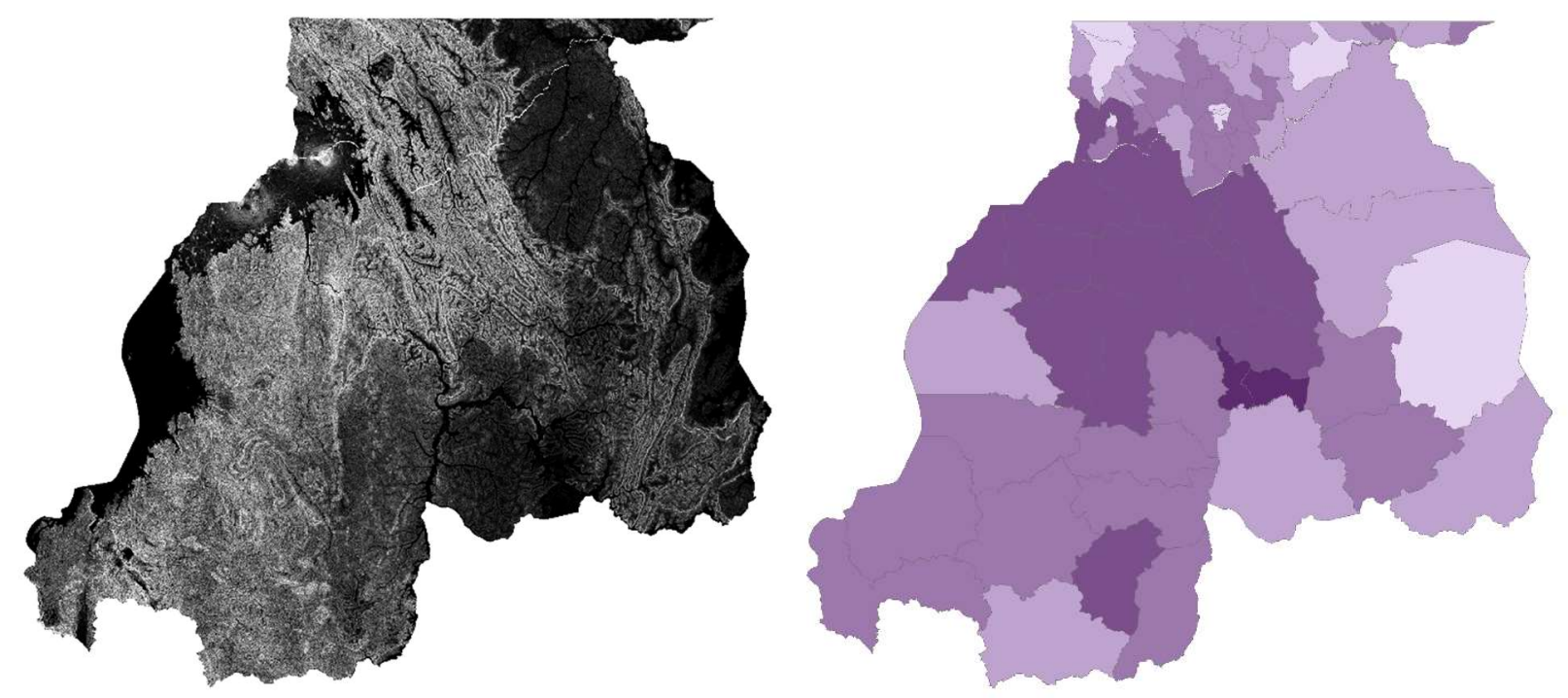

Figure 9. Granularity Differences between Slope 30 meter (left) and Population Density 30 meter (right)

Another spatial imprecision in this study may exist between the landslide points created in Google Earth and their respective locations on the DEM layers. Although all layers were projected to the same coordinate system, no analysis was performed to check the accuracy of 
locations. If possible, a coregistration process to ensure the layers were aligned would have helped. Another method to avoid error would be to use a 3 square sampling method when collecting the DEM-derived variable data- where the neighboring pixels around each landslide point are also sampled and averaged into the final value.

A solution to this would be crowd-sourcing the data collection. If a landslide reporting phone app or call-in number was made available to the public, GPS locations and times of landslides could be collected as they are observed. Another way to achieve this could be scraping social media, like Twitter, for references to landslides in Rwanda.

A statistical methodology does have some unique limitations. There is a tendency to simplify the factors of landslides, by only choosing variables that can be relatively easily mapped or derived from a DEM (van Westen 2006). In this study, 50+ variables were initially considered, but that list was narrowed due to keep the project within time constraints. Variables removed were duplicates by different names, variables that may have an unclear link to landslides, and variables that would be difficult to acquire or calculate data for. This leads to some bias in variable selection.

Another limitation is assuming that all landslides occur under the same combination of conditions throughout the study area (van Westen 2006). This is a tradeoff between doing a time consuming but highly specific set of studies and providing an estimate for a larger region. In this study, this limitation is offset by the relatively small area of Rwanda. Any detrimental error is checked for in the accuracy assessment step.

Lastly, precipitation is an important variable, but not appropriately addressed in this general study. Therefore, this was examined in the more focused landslide study. 


\subsection{Focused Study Discussion}

TRMM data for 16 years plotted as a time series indicated a yearly pattern of intense precipitation events (Figure 11). Precipitation ranged from zero up to a maximum of approximately $68 \mathrm{~mm} /$ day in 2010 in the low landslide density part of the study area. The time series clearly show the seasonal pattern of rainfall with two broad rainy periods each year separated by periods of no or low precipitation (Figure 10). The time series for the low landslide density pixel has its five highest peaks in 2001, 2003, 2009, 2010, and 2012 ( 
Table 3).

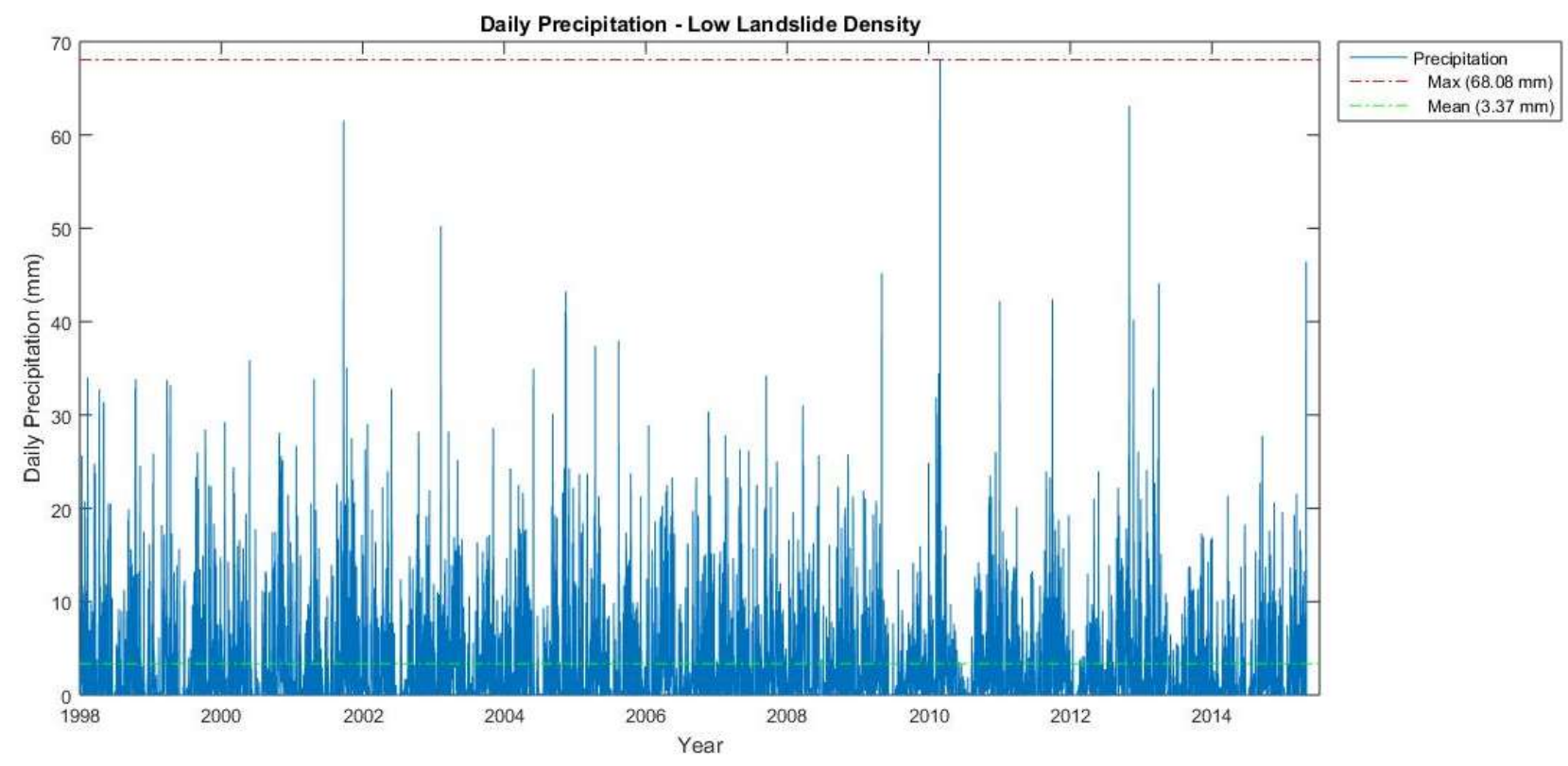

Figure 10. Daily precipitation in Low Landslide Density study area-precipitation values in $\mathrm{mm} /$ day are shown for 16 years of available TRMM data. The maximum precipitation value was $68.08 \mathrm{~mm} /$ day (red dot-dashed line), and the mean was 3.37 $\mathrm{mm} /$ day (green dot-dashed line).

In the high landslide density part of the study area, the precipitation ranged from zero up to a maximum of approximately $56 \mathrm{~mm}$ /day in 2001 (Figure 11). The seasonal pattern of rainy and dry seasons can again be seen. The time series for the high landslide density area has its five largest peaks in 1999, 2001, 2007, 2010, and 2013 ( 
Table 3).

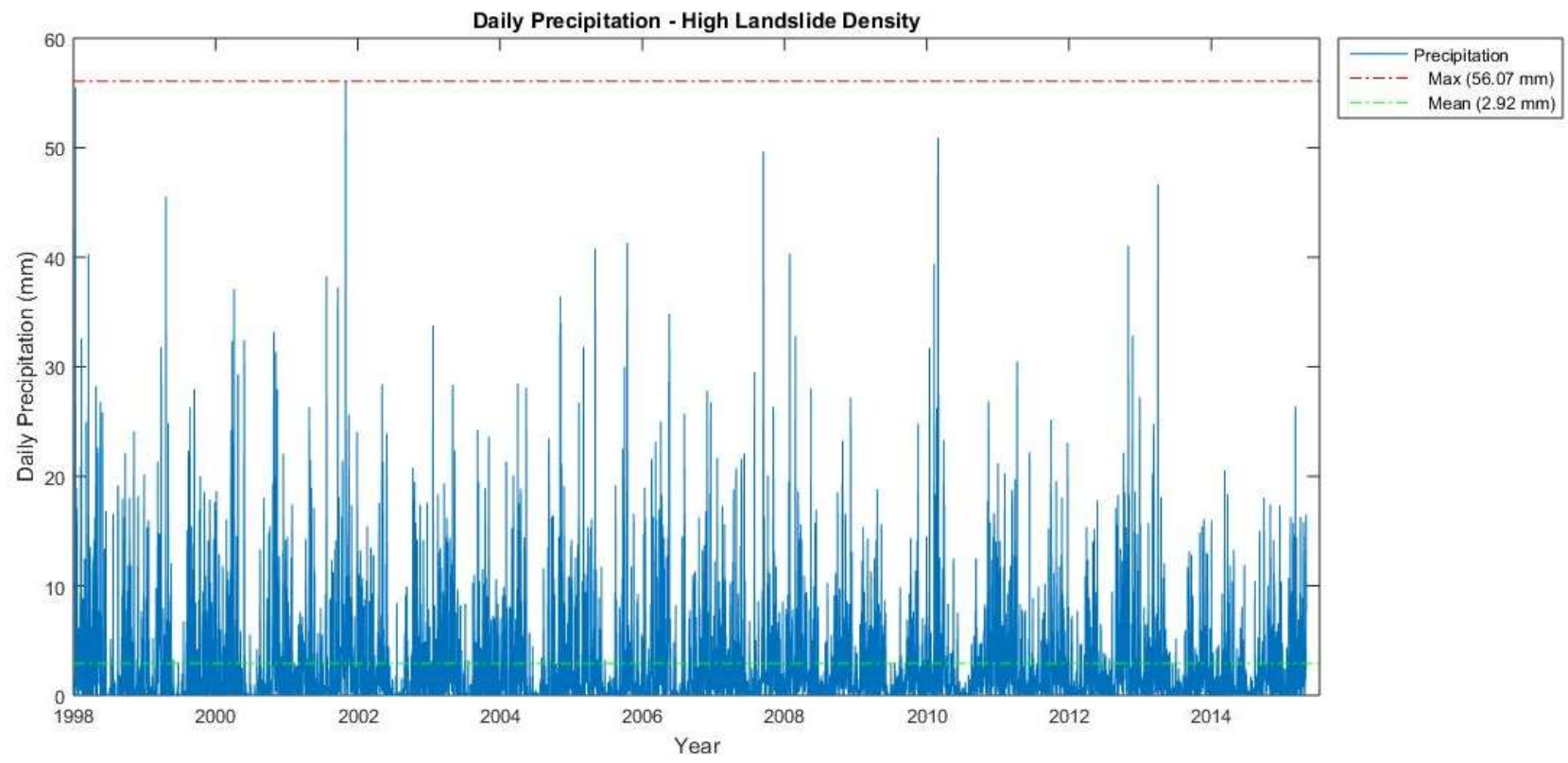

Figure 11. Daily precipitation in the High Landslide Density study area - precipitation values in $\mathrm{mm} /$ day are shown for 16 years of available TRMM data. The maximum precipitation value was $56.07 \mathrm{~mm} /$ day (red dot-dashed line), and the mean was 2.93 $\mathrm{mm} /$ day (green dot-dashed line). 
Table 3. Top five precipitation values for high and low landslide density areas

\begin{tabular}{ccc}
\hline \multicolumn{3}{c}{ High Landslide Density } \\
& \multicolumn{2}{c}{$\begin{array}{l}\text { Precipitation in } \\
\text { Low Landslide }\end{array}$} \\
Date & $\begin{array}{l}\text { Precipitation } \\
\text { (mm/day) }\end{array}$ & $\begin{array}{l}\text { Density Region on } \\
\text { this day (mm/day) }\end{array}$ \\
\hline $4 / 21 / 1999$ & 45.53 & 17.34 \\
$10 / 30 / 2001$ & 56.07 & 12.85 \\
$9 / 15 / 2007$ & 49.65 & 34.25 \\
$2 / 28 / 2010$ & 50.91 & 68.08 \\
$4 / 2 / 2013$ & 46.62 & 44.13 \\
\hline \hline & & \\
\hline & & \\
\hline & & Precipitation in \\
& & High Landslide \\
& & Density Region on \\
Date & & this day (mm/day) \\
\hline $9 / 24 / 2001$ & 61.54 & 13.04 \\
$2 / 8 / 2003$ & 50.23 & 5.173 \\
$5 / 3 / 2009$ & 45.21 & 7.58 \\
$2 / 28 / 2010$ & 68.08 & 50.91 \\
$11 / 1 / 2012$ & 63.12 & 41.05 \\
\hline \hline
\end{tabular}

The high landslide density region has precipitation peaks that don't match the peaks in the low landslide density region. The one peak they both have in common is $2 / 28 / 2010$. To compare and see if there is a corresponding peak in landslide occurrence, I produced a plot of number of landslides per year (Figure 12). Landslides are classified by the year they were first observed in satellite imagery. This shows that the majority of landslides mapped occurred in 2014 or 2015, and a few in earlier years. There are large gaps in time where no landslides were mapped, and the peak precipitation dates in 
Table 3 don't correlate to dates for landslides that were mapped. This is most likely because satellite imagery is not available for all years. Satellite data is not available for most of the years identified by TRMM as having a peak rainfall value.

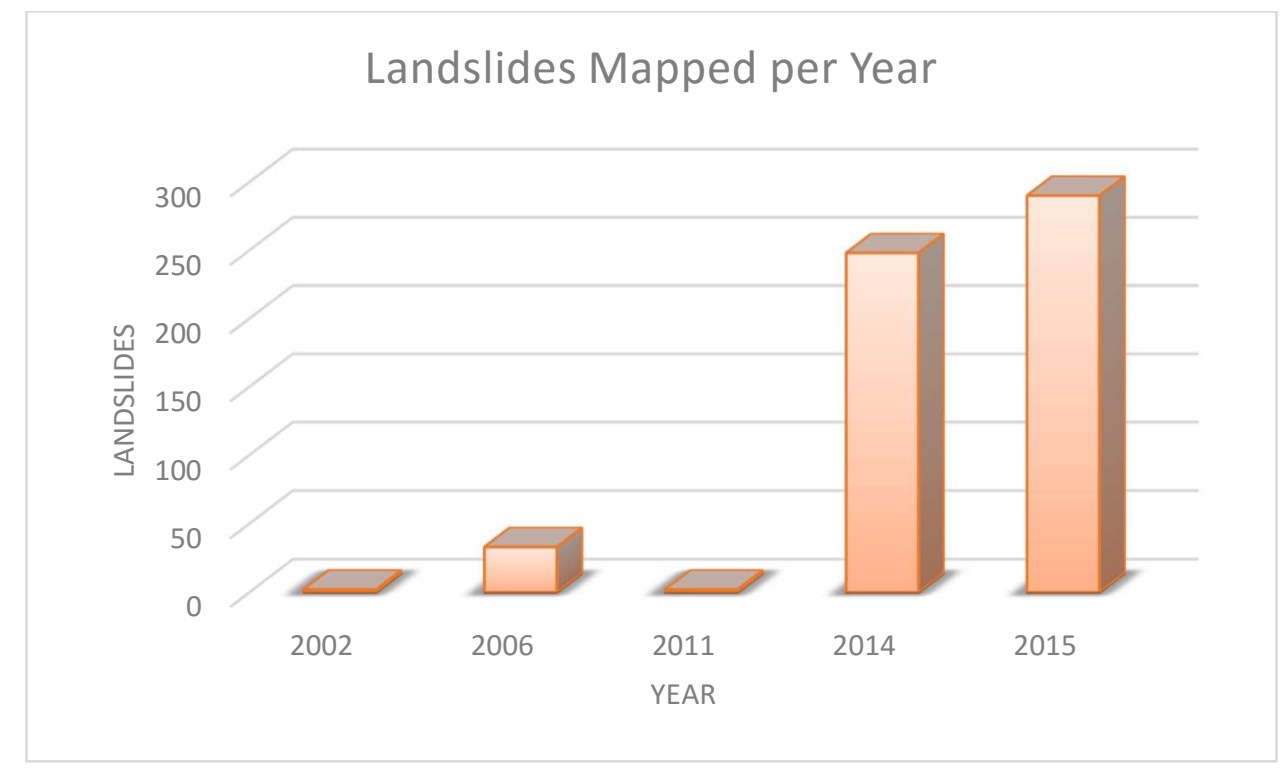

Figure 12. Number of landslides mapped per year. Landslides are classified by the year they first appeared in satellite images.

This means they occurred this year, or earlier. Years not shown either had no landslides, or no suitable satellite imagery available on Google Earth.

The areas of mapped landslides range from 1 to $317,900 \mathrm{~m}^{2}$. I split the areas of landslides into bins of $1000 \mathrm{~m}^{2}$ size, and plotted the distribution on a log-log scale (Figure 13). Landslide areas generally ranged from 0 to $3500 \mathrm{~m}^{2}$, with several extremely large $\left(>100,000 \mathrm{~m}^{2}\right)$ slides. The data are approximately power-law distributed, which indicates that relatively rare but very large events may play an important role in setting the landslide erosion rate. 


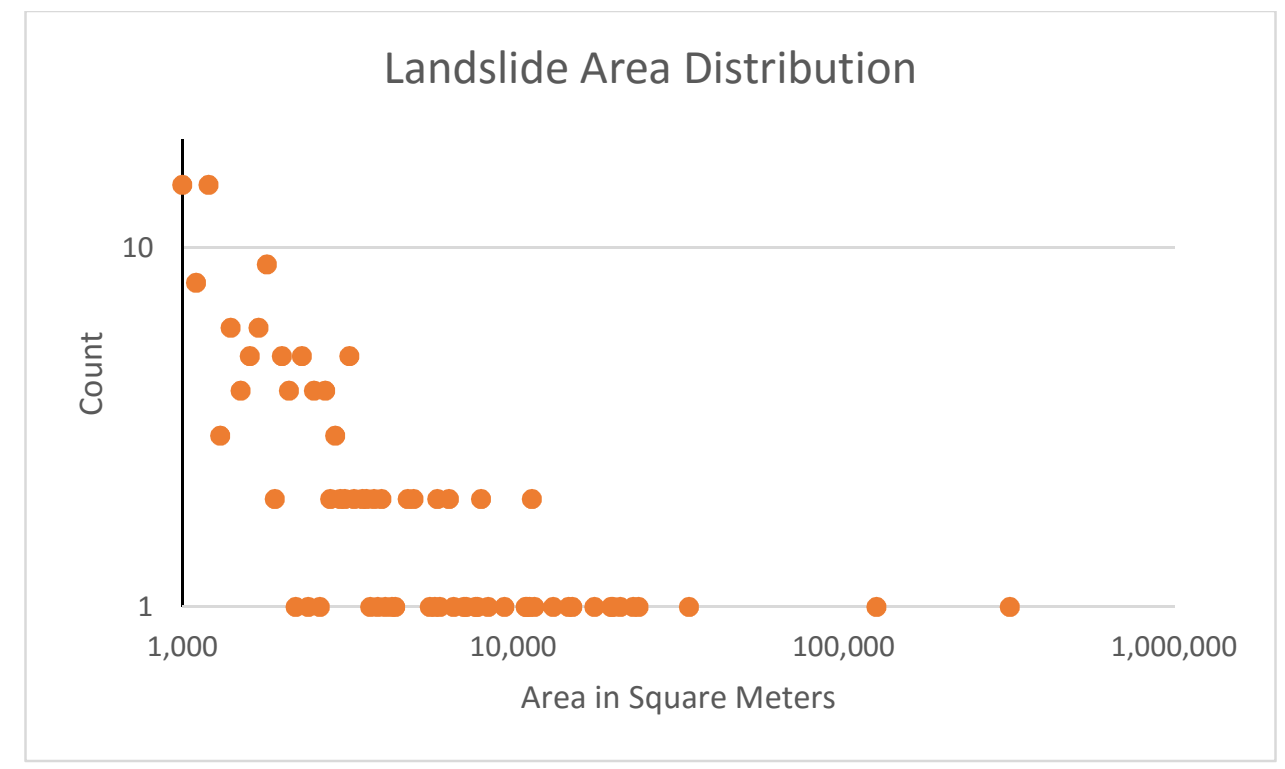

Figure 13. Distribution of Landslide Area in square meters. 577 mapped landslides in the high density area are split into $1000 \mathrm{~m}^{2}$ bins and plotted. The majority of landslides mapped are between 0 and $3500 \mathrm{~m}^{2}$ in area and the largest landslide mapped is $317,900 \mathrm{~m}^{2}$. The few extremely large landslides leads to a long tail distribution.

In one more attempt to compare or contrast precipitation for the high density landslide area and the low landslide density area, I plotted precipitation versus recurrence interval for each region (Figure 14). The largest storm events for the high density and the low density regions occurred on different dates, and were a variety of sizes, but when the precipitation versus recurrence interval plots are shown on the same axis, it is clear that they are extremely similar. Despite the different dates for the storm events, the overall precipitation distribution is very similar for both the high density and low density regions. 


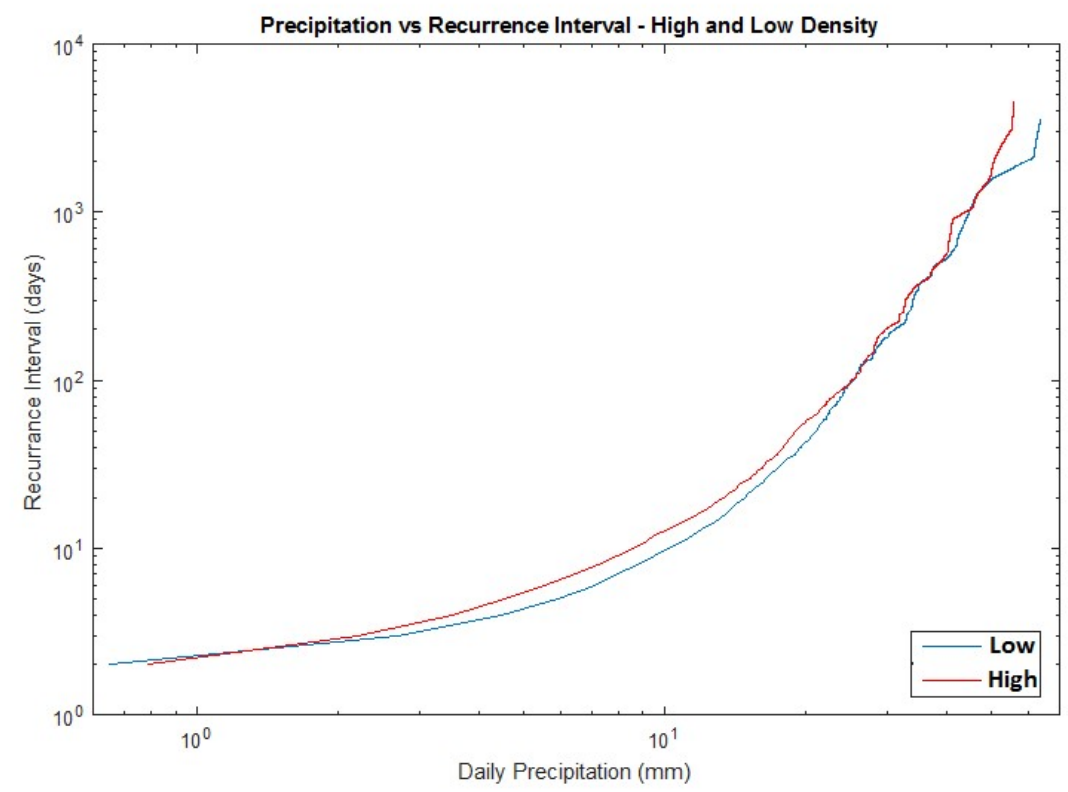

Figure 14 Recurrence Interval vs. precipitation for low and high landslide density areas. Despite the fact that dates for storms were different, the overall precipitation pattern for the two regions is very similar.

\subsection{Focused Study Discussion}

The high landslide density region and the low landslide density region are not notably different in rainfall- overall, the time series for both regions look very similar. A relationship between precipitation and landslide density was not developed and the null hypothesis cannot be ruled out. This apparent lack of connection could result from several aspects of the available data and nature of the study area.

First, perhaps the grid size $\left(0.25^{\circ}\right.$ by $\left.0.25^{\circ}\right)$ for the TRMM data is too large for this type of study, and relevant rainstorms are going "unseen" as they are smaller than the grid. This would assume that concentrated weather events that are more likely to trigger landslides are smaller than $0.25^{\circ}$ by $0.25^{\circ}$ (approximately $780 \mathrm{~km}^{2}$ in the study area). This is also a problem that Turner et al. (2010) encountered in their study of landslide densities in Washington state. The TRMM data was not sufficiently accurate to capture rainfall amounts for the landslides they 
studied. This could be addressed by finding a different source of rainfall data with a smaller spatial grid, designing and deploying a rain gage system, or by interpreting precipitation through other related variables, like type of groundcover or measuring soil moisture, which can be estimated remotely via NASA's Soil Moisture Active Passive (SMAP) mission. SMAP was not used for this study because the google earth images available covered (2006 - mid 2015) and SMAP data is only consistently available after November, 2015. Soil Moisture can also be approximated from surface temperature and vegetation index, which can in turn be sourced from satellite data (Holzman et al. 2014).

While the spatial grid for TRMM was larger than desired, the temporal resolution (daily) was excellent, much better than the satellite imagery currently available. In contrast to this, high resolution topographic data from techniques such as airborne LIDAR would be excellent spatially, but not sufficient temporally due to cost and logistical constraints.

Satellite imagery could also be affecting the results because the temporal resolution is approximately yearly to decadal. In this study area, there were no satellite images for the years in which peak rainfall occurred, so landslides triggered by those storms might not be visible in the more recent imagery. Most of the study area is in agricultural land, and landslide scars are often re-planted or otherwise obscured within a few years of the landslide. It is likely that landslides are being promptly cleaned up and vegetation quickly grows back over or is replanted in landslide areas. Some landslides will not show up on satellite imagery unless they were very recent. But not all landslides in Rwanda seem to act this way- some landslides continue to be visible in many years of satellite imagery. 
Landslides mapped as occurring in 2014 or 2015 could have occurred in earlier years. This could be addressed by purchasing satellite imagery for specific years after analyzing the precipitation data for a study area.

Alternatively, an unconsidered factor could be more significant, such as antecedent soil moisture. This could be a reason why a landslide would not tie directly to a storm event, but instead lag after, or not be triggered until a second storm event.

A change in data quality, be it satellite imagery or mapping technique, could also be relevant. Some years of satellite imagery are very dark images, and some years are better resolution than others. A landslide is more likely to be spotted on a lighter image with higher contrast than a darker, low contrast image. Especially combined with questionable image quality, mapping bias can lead to a lower quality landslide inventory than field mapping, even when conducted by experts (Van Den Eeckhaut 2005).

\section{Conclusions and Implications}

Landslide hazard in Rwanda is largely dependent on the slope of the topography and anthropogenic factors. Considering only these two factors, landslide hazard can be predicted with about an $80 \%$ accuracy. Water plays a large role in landsliding in Rwanda, with high intensity precipitation events of 40-50 mm/day occurring annually. The specific mechanism of how water is triggering landsides is difficult to determine from freely available satellite imagery and precipitation data.

In general, the effects of landslides are more significant in Rwanda than they would be in another location, all other factors being the same. It is estimated that $90 \%$ of urban housing is met through "informal settlements", cheap unplanned housing in inappropriate locations with steep slopes and poor drainage (UNEP 2011). 
While a complete picture of precipitation for the country of Rwanda is not available, this focused study shows a relationship between storm size and widespread land sliding. Available data suggests Rwanda experiences irregular and unpredictable rainfall patterns. One predicted effect of climate change is an increase in the kind of extreme rainfall events that cause flooding and landslides (UNEP 2011). This means conditions will continue or worsen, and landslide hazard mapping and landslide prediction are more crucial now than ever.

There are processes in place to improve some of Rwanda's land management practices, including buffers on farming and building, moving populations from the most dangerous locations, and green practices. However, they are not well enforced, and it is a slow process to get these to a level where they make a difference. Environmental governance is strong, though, and good policies have been established- destructive flooding and landslides, droughts and food insecurity have not gone unnoticed. Decentralization of government has also allowed regional communities to have a larger voice in environmental governance (UNEP 2011)

\section{Acknowledgements}

I thank Portland State University, NASA, SERVIR, and the Oregon Space Grant. Additional thanks to the Tropical Rainfall Measuring Mission (TRMM) and Goddard Earth Sciences Data and Information Services Center (GES DISC) for the dissemination of TRMM data. 


\section{References}

Anderson, E.R., 2012, Analysis of rainfall-triggered landslide hazards through the dynamic integration of remotely sensed, modeled and in situ environmental factors in El Salvador [Masters Thesis]: Huntsville, The University of Alabama in Huntsville, 191 p.

Ballard, H., 2015, Landslide Hazard Analysis in Rwanda and Southern Uganda [Report]: Huntsville, NASA/SERVIR

Byers, A.C. 1992, Soil loss and sediment transport during the storms and landslides of May 1988 in Ruhengeri Prefecture, Rwanda. Natural Hazards v. 5, p. 279 - 292.

Central Intelligence Agency (CIA), 2015, Country Comparison: Area. The World Factbook: https://www.cia.gov/library/publications/the-world-factbook/geos/rw.html (accessed $8 / 17 / 2015)$

Dai, F. C., Lee, C. F., 2003. A spatiotemporal probabilistic modelling of storm-induced shallow landsliding using aerial photographs and logistic regression. Earth Surface Processes and Landforms, v. 28, p. 527 - 545

Dai, F.C., Lee, C.F., Ngai, Y.Y., 2002. Landslide risk assessment and management- an overview. Engineering Geology v. 64, p. 65-87.

Dusková, M.,; Machácek, J., Smolová, I., 2014, The geomorphological changes caused by the artisanal mining in the mining area Kabera - Rwanda, in Proceedings, International Multidisciplinary Scientific GeoConference : SGEM : Surveying Geology \& mining Ecology Management, Sofia, Bulgaria: v. 3, p. 673-679.

eSoko, 2015,Republic of Rwanda Ministry of Agriculture and Animal Resources: About e-Soko: http://www.esoko.gov.rw/esoko/Dashboard/Login.aspx?DashboardId=4\&dash=true\&Log in=true (accessed July 2015)

Expert Africa, 2015, Rwanda Weather and Climate:https://www.expertafrica.com/rwanda/info/rwanda-weather-and-climate (accessed December 2015)

Feldman, J., Byxbe, V., 2014. Landslide Hunting in East Africa [Report]: Huntsville, NASA/SERVIR.

Guzzetti, F., Carrara A., Cardinali M., Reichenbach P., 1999, Landslide hazard evaluation: a review of current techniques and their application in a multi-scale study, Central Italy, Geomorphology v. 31 p. 181-216.

Holzman, M. E., Rivas, R., Piccolo, M.C., 2014, Estimating soil moisture and the relationship with crop yield using surface temperature and vegetation index, International Journal of Applied Earth Observation and Geoinformation v.28: p.181 - 192.

Iverson, R. M., Reid, M., Iverson, N. R., LaHusen, R. G., Logan, M., Mann, J. E., Brien, D.L., 2000, Acute sensitivity of landslide rates to initial soil porosity, Science, v. 290, p. $513-$ 516. 
Iverson, R. M., 2005, Regulation of landslide motion by dilatancy and pore pressure feedback,Journal of Geophysical Research, v. 110 iss.F2 p. 2156 - 2202.

Kirschbaum, D.B., Adler, R., Hong, Y., Hill, S., Lerner-Lam, A., 2010, A global landslide catalog for hazard applications: method, results, and limitations, Natural Hazards, v. 52, p. $561-575$.

Kirschbaum, D. B., Adler, R., Hong, Y., Lerner-Lam, A., 2009, Evaluation of a preliminary satellite-based landslide hazard algorithm using global landslide inventories, Natural Hazards and Earth System Sciences, v. 9, p. 673 - 686.

Kirschbaum, D.B., Adler, R., Hong, Y., Kumar, S., Peters-Lidard, C., Lerner-Lam, Arthur. 2012. Advances in landslide nowcasting: evaluation of a global and regional modeling approach. Environmental Earth Science, v66, p. 1683-1696.

Kirschbaum, D., Stanley, T., Zhou, Y., 2015, Spatial and temporal analysis of a global landslide catalog, Geomorphology, v. 249, p. 4-15.

Koutsias, N., Karteris, M., 1998, Logistic regression modelling of multitemporal Thematic Mapper data for burned area mapping, International Journal of Remote Sensing, v.19, iss. 18, p.3499-3514. DOI: 10.1080/014311698213777

LP DAAC, 2014, NASA Shuttle Radar Topography Mission: https://lpdaac.usgs.gov. (accessed $8 / 20 / 2015)$

Metternicht, G., Hurni, L., Gogu, R., 2005, Remote sensing of landslides: An analysis of the potential contribution to geo-spatial systems for hazard assessment in mountainous environments, Remote Sensing of Environment v. 98, p. 284-303.

Montgomery, D.R., Dietrich, W. E., Heffner, J.T., 2002, Piezometric response in shallow bedrock at CB1: Implications for runoff generation and landsliding, Water Resources Research, v. 38, no. 12, p. 1274, doi:10.1029/2002WR001429

NASA GSFC, 2016, TRMM Tropical Rainfall Measuring Mission: http://trmm.gsfc.nasa.gov/. (accessed February 2016)

NASA JPL, 2016, SMAP Soil Moisture Active Passive: Mission Description: http://smap.jpl.nasa.gov/mission/description/ (accessed February 2016)

National Institute of Statistics of Rwanda (NISR), Ministry of Finance and Economic Planning (MINECOFIN) [Rwanda], 2012 Fourth Rwanda Population and Housing Census. Final Results: Main indicators report (2014)

Peng, C.J., Lee, K.L., Ingersoll, G.M. 2002, An Introduction to Logistic Regression Analysis and Reporting, The Journal of Educational Research, v. 96, iss. 1, p. 1-13.

Petley, D., 2012, Global patterns of loss of life from landslides, Geology 40, no. 10, pp 927 930. DOI: $10.1130 / \mathrm{G} 33217.1$ 
Piller, A. N., 2015, Landslide Hazard Mapping in Rwanda Using Logistic Regression, [Report]: Huntsville, NASA/SERVIR

Ritter, D.F., Kochel, R. C., Miller, J.R., 2011, Process Geomorphology, Fifth Edition. Long Grove, IL, USA, Waveland Press, Inc., 652 p.

SERVIR, 2015, https://www.servirglobal.net/ (accessed August 2015)

SYSTAT Software, Inc., 2007. MYSTAT 12 Help: Correlations, Logistic Regression

Terzaghi, K., 1950, Mechanism of Landslides, Engineering Geology (Berkey Volume), Washington D. C., Geological Society of America, p. $91-94$.

Turner, T.R., Duke, S.D., Fransen, B.R., Reiter, M.L., Kroll, A.J., Ward, J.W., Bach, J.L., Justice, T.E., Bilby, R.E., 2010. Landslide densities associated with rainfall, stand age, and topography on forested landscapes, southwestern Washington, USA. Forest Ecology and Management v. 259, p. 2233-2247.

United Nations Environment Programme (UNEP) 2011 Report, 2011, Rwanda: From PostConflict to Environmentally Sustainable Development: Nairobi, Kenya, United Nations Environment Programme, $379 \mathrm{p}$.

USGS, 2014, Landslide 101 http://landslides.usgs.gov/learn/ls101.php (accessed August 2015)

Van Den Eeckhaut, M., Poesen, J., Verstraeten, G., Vanacker, V., Moeyersons, J., Nyssen, J., Van Beek, L. P. H. 2005. The effectiveness of hillshade maps and expert knowledge in mapping old deep-seated landslides. Geomorphology, v. 67(3), p. 351-363.

van Westen, C.J., van Asch, T.W.J., Soeters, R., 2006, Landslide hazard and risk zonation- why is it still so difficult?, Bulletin of Engineering Geology and the Environment, v. 65, p. $167-184$.

Varnes, D.J., 1984. Landslide hazard zonation: a review of principles and practice. Paris, France, United Nations International, $63 \mathrm{p}$.

$\mathrm{Xu}, \mathrm{C} ., 2015$, Preparation of earthquake-triggered landslide inventory maps using remote sensing and GIS technologies: Principles and case studies, Geoscience Frontiers v. 6, p. 825-836. 


\title{
Appendix A: Landslide Inventory for Focused Study
}

\author{
Appendix B: Matlab Script
}


2016 Focused Study (Precipitation) Landslide Inventory

\begin{tabular}{|c|c|c|c|c|c|}
\hline Name & Landslide Date & Area & $\begin{array}{l}\text { Latitude (In decimal } \\
\text { degrees) }\end{array}$ & $\begin{array}{l}\text { Longitude (In decimal } \\
\text { degrees) }\end{array}$ & Notes \\
\hline 1 & 2015 & 539.125661 & -2.028604 & 29.567261 & \\
\hline 2 & 2015 & 236.92899 & -2.028811 & 29.567405 & \\
\hline 3 & 2015 & 7173.678658 & -2.029197 & 29.567697 & \\
\hline 4 & 2015 & 598.927618 & -2.029278 & 29.566756 & \\
\hline 5 & 2015 & 101.168661 & -2.027119 & 29.567356 & \\
\hline 6 & 2015 & 156.2059 & -2.028641 & 29.566082 & \\
\hline 7 & 2015 & 412.203142 & -2.027925 & 29.566068 & \\
\hline 8 & 2015 & 155.664567 & -2.028482 & 29.565933 & \\
\hline 9 & 2015 & 470.428732 & -2.027105 & 29.566132 & \\
\hline 10 & 2015 & 1239.082116 & -2.024025 & 29.566251 & \\
\hline 11 & 2015 & 752.180507 & -2.022613 & 29.566691 & \\
\hline 12 & 2015 & 260.168472 & -2.023064 & 29.566895 & \\
\hline 13 & 2015 & 82.050746 & -2.023118 & 29.566462 & \\
\hline 14 & 2015 & 7749.290889 & -2.022528 & 29.565684 & \\
\hline 15 & 2015 & 979.297688 & -2.021347 & 29.565737 & \\
\hline 16 & 2015 & 3491.979157 & -2.021154 & 29.565272 & \\
\hline 17 & 2015 & 127.354558 & -2.026888 & 29.564455 & \\
\hline 18 & 2015 & 370.341859 & -2.026109 & 29.565204 & \\
\hline 19 & 2015 & 98.547386 & -2.025811 & 29.565282 & \\
\hline 20 & 2015 & 958.141349 & -2.025754 & 29.566156 & \\
\hline 21 & 2015 & 366.064807 & -2.026247 & 29.566239 & \\
\hline 21 & 2015 & 150.628973 & -2.025573 & 29.566594 & \\
\hline 22 & 2015 & 145.933746 & -2.025715 & 29.566726 & \\
\hline 23 & 2015 & 3121.359719 & -2.026215 & 29.56739 & \\
\hline 24 & 2015 & 2404.261381 & -2.025447 & 29.567275 & \\
\hline 25 & 2015 & 241.29347 & -2.025809 & 29.570409 & \\
\hline 26 & 2014 & 402.296679 & -2.020398 & 29.569499 & and 2015 \\
\hline 27 & 2014 & 4911.71597 & -2.020845 & 29.569962 & and 2015 \\
\hline 28 & 2015 & 340.814179 & -2.021666 & 29.570663 & \\
\hline 29 & 2015 & 23955.18473 & -2.015543 & 29.572446 & \\
\hline 30 & 2015 & 3750.092038 & -2.030634 & 29.567938 & \\
\hline 31 & 2015 & 215.710425 & -2.030657 & 29.566253 & \\
\hline 32 & 2015 & 1905.490242 & -2.005745 & 29.573828 & \\
\hline 33 & 2015 & 334.369729 & -1.995215 & 29.561609 & \\
\hline 34 & 2015 & 503.641659 & -1.994989 & 29.561811 & \\
\hline 35 & 2015 & 49.288274 & -1.995527 & 29.561254 & \\
\hline 36 & 2015 & 138.56606 & -2.042492 & 29.563964 & \\
\hline 37 & 2015 & 807.248678 & -2.02933 & 29.579075 & \\
\hline 38 & 2015 & 150.756345 & -2.023017 & 29.578714 & \\
\hline 39 & 2015 & 163.136565 & -2.023379 & 29.579396 & \\
\hline 40 & 2015 & 588.108088 & -2.01676 & 29.594005 & \\
\hline 41 & 2015 & 3703.565082 & -2.010219 & 29.586061 & \\
\hline 42 & 2014 & 2994.984557 & -2.000861 & 29.597718 & \\
\hline 43 & 2014 & 5920.57838 & -2.000724 & 29.599124 & \\
\hline 44 & 2014 & 317859.5599 & -1.998161 & 29.601806 & \\
\hline 45 & 2014 & 187.609066 & -1.995767 & 29.602294 & \\
\hline 46 & 2014 & 374.711407 & -1.995548 & 29.602255 & \\
\hline 47 & 2014 & 1060.949284 & -1.995023 & 29.602124 & \\
\hline 48 & 2014 & 782.913619 & -1.994352 & 29.601427 & \\
\hline 49 & 2014 & 2081.693589 & -1.994341 & 29.60095 & \\
\hline 50 & 2014 & 1116.876015 & -1.993782 & 29.60081 & \\
\hline 51 & 2014 & 54.049036 & -1.993518 & 29.600686 & \\
\hline 52 & 2014 & 129.379695 & -1.994046 & 29.600526 & \\
\hline 53 & 2014 & 19745.47216 & -1.994342 & 29.597824 & \\
\hline 54 & 2014 & 11360.22353 & -1.991121 & 29.59687 & \\
\hline 55 & 2014 & 3557.685817 & -1.993077 & 29.598021 & \\
\hline 56 & 2014 & 1006.398639 & -1.992961 & 29.599214 & \\
\hline 57 & 2014 & 137.737199 & -1.992778 & 29.599361 & \\
\hline 58 & 2014 & 174.967966 & -1.992548 & 29.599365 & \\
\hline 59 & 2014 & 1679.961678 & -1.992288 & 29.597825 & \\
\hline
\end{tabular}


2016 Focused Study (Precipitation) Landslide Inventory

\begin{tabular}{|c|c|c|c|c|c|}
\hline Name & Landslide Date & Area & $\begin{array}{l}\text { Latitude (in decimal } \\
\text { degrees) }\end{array}$ & $\begin{array}{l}\text { Longitude (in decimal } \\
\text { degrees) }\end{array}$ & Notes \\
\hline 60 & 2014 & 11153.2399 & -1.988014 & 29.601006 & \\
\hline 61 & 2014 & 258.999625 & -1.989334 & 29.59919 & \\
\hline 62 & 2014 & 206.334238 & -1.988924 & 29.598896 & \\
\hline 63 & 2014 & 398.5662 & -1.986035 & 29.600249 & \\
\hline 64 & 2014 & 837.156768 & -1.985263 & 29.599853 & \\
\hline 65 & 2014 & 2712.352529 & -1.987575 & 29.604423 & \\
\hline 66 & 2014 & 419.967901 & -1.99309 & 29.60958 & \\
\hline 67 & 2014 & 7038.60939 & -1.985195 & 29.596043 & \\
\hline 68 & 2014 & 4902.299026 & -1.986652 & 29.596242 & \\
\hline 69 & 2011 & 6382.690435 & -1.986382 & 29.597854 & and 2014 \\
\hline 70 & 2014 & 3160.17886 & -1.995753 & 29.606446 & \\
\hline 71 & 2014 & 1079.084765 & -2.017914 & 29.603753 & \\
\hline 72 & 2014 & 222.529013 & -2.016622 & 29.597572 & \\
\hline 73 & 2015 & 882.139249 & -2.024047 & 29.571281 & \\
\hline 74 & 2015 & 849.17498 & -2.012795 & 29.570846 & \\
\hline 75 & 2015 & 364.002969 & -2.011933 & 29.570538 & \\
\hline 76 & 2014 & 6327.868677 & -2.011736 & 29.585698 & looks older \\
\hline 77 & 2014 & 242.409995 & -2.043804 & 29.600785 & \\
\hline 78 & 2014 & 1203.888111 & -2.041811 & 29.597189 & \\
\hline 79 & 2014 & 186.955279 & -2.02385 & 29.615983 & \\
\hline 80 & 2014 & 90.22386 & -2.023442 & 29.631857 & \\
\hline 81 & 2014 & 288.902814 & -2.014284 & 29.624983 & \\
\hline 82 & 2014 & 219.91366 & -2.015525 & 29.615917 & \\
\hline 83 & 2014 & 28.262073 & -2.010895 & 29.631583 & \\
\hline 84 & 2014 & 275.071084 & -1.997739 & 29.628861 & \\
\hline 85 & 2014 & 274.121166 & -2.002926 & 29.628007 & \\
\hline 86 & 2014 & 11372.40679 & -1.978833 & 29.617738 & \\
\hline 87 & 2014 & 1188.482634 & -1.986394 & 29.631285 & \\
\hline 88 & 2014 & 208.710596 & -1.990926 & 29.623742 & \\
\hline 89 & 2014 & 91.980959 & -1.987616 & 29.579747 & \\
\hline 90 & 2014 & 146.078996 & -1.987051 & 29.580088 & \\
\hline 91 & 2014 & 79.661488 & -1.986736 & 29.579655 & \\
\hline 92 & 2014 & 115.741526 & -1.986621 & 29.579734 & \\
\hline 93 & 2014 & 81.571111 & -1.98645 & 29.57978 & \\
\hline 94 & 2014 & 142.05696 & -1.983741 & 29.590187 & \\
\hline 95 & 2014 & 2646.215047 & -1.980184 & 29.595329 & \\
\hline 96 & 2014 & 410.084362 & -1.975975 & 29.562988 & \\
\hline 97 & 2015 & 955.593252 & -1.976266 & 29.572052 & \\
\hline 98 & 2015 & 921.003641 & -1.97652 & 29.572191 & \\
\hline 99 & 2015 & 339.437331 & -1.979397 & 29.570507 & \\
\hline 100 & 2015 & 61.290744 & -1.987839 & 29.574214 & \\
\hline 101 & 2015 & 481.844741 & -1.988456 & 29.562708 & \\
\hline 102 & 2015 & 60.047511 & -1.948026 & 29.571985 & \\
\hline 103 & 2015 & 671.503334 & -1.945951 & 29.563657 & \\
\hline 104 & 2015 & 483.186676 & -1.986251 & 29.56182 & \\
\hline 105 & 2015 & 289.396923 & -1.986721 & 29.561509 & \\
\hline 106 & 2015 & 405.810595 & -1.957717 & 29.56801 & \\
\hline 107 & 2015 & 230.726429 & -1.981198 & 29.559253 & \\
\hline 108 & 2015 & 366.79361 & -1.98126 & 29.5594 & \\
\hline 109 & 2014 & 686.402283 & -2.020783 & 29.551611 & \\
\hline 110 & 2014 & 593.272197 & -2.020512 & 29.551856 & \\
\hline 111 & 2014 & 83.764581 & -2.020492 & 29.552039 & \\
\hline 112 & 2014 & 33903.72826 & -2.018671 & 29.550718 & \\
\hline 113 & 2014 & 517.973992 & -2.019297 & 29.55173 & \\
\hline 114 & 2014 & 182.935514 & -2.019177 & 29.551393 & \\
\hline 115 & 2015 & 541.667011 & -2.020133 & 29.550615 & \\
\hline 116 & 2014 & 417.878769 & -2.022123 & 29.54816 & \\
\hline 117 & 2014 & 195.691399 & -2.022016 & 29.547613 & \\
\hline 118 & 2014 & 163.44081 & -2.0279 & 29.55275 & \\
\hline 119 & 2014 & 56.396134 & -2.028366 & 29.550329 & \\
\hline
\end{tabular}


2016 Focused Study (Precipitation) Landslide Inventory

\begin{tabular}{|c|c|c|c|c|c|c|}
\hline Name & Landslide Date & & Area & $\begin{array}{l}\text { Latitude (in decimal } \\
\text { degrees) }\end{array}$ & $\begin{array}{l}\text { Longitude (in decimal } \\
\text { degrees) }\end{array}$ & Notes \\
\hline 120 & & 2014 & 69.421082 & -2.02792 & 29.548657 & \\
\hline 121 & & 2015 & 55.959335 & -2.028083 & 29.545502 & \\
\hline 122 & & 2014 & 8330.70205 & -2.003462 & 29.551113 & \\
\hline 123 & & 2015 & 3001.350495 & -2.002717 & 29.549532 & \\
\hline 124 & & 2015 & 5761.418147 & -1.995628 & 29.543946 & \\
\hline 125 & & 2015 & 116.832083 & -1.993027 & 29.555298 & \\
\hline 126 & & 2015 & 161.624913 & -1.993237 & 29.554903 & \\
\hline 127 & & 2015 & 2008.649055 & -1.989672 & 29.556741 & \\
\hline 128 & & 2015 & 133.796854 & -1.985351 & 29.552441 & \\
\hline 129 & & 2015 & 279.366336 & -1.990169 & 29.556005 & \\
\hline 130 & & 2015 & 1170.315411 & -2.029867 & 29.55428 & \\
\hline 131 & & 2015 & 251.392124 & -2.044639 & 29.546596 & \\
\hline 132 & & 2015 & 165.157855 & -2.044705 & 29.546805 & \\
\hline 133 & & 2014 & 53.760219 & -1.971352 & 29.603501 & \\
\hline 134 & & 2014 & 935.375833 & -1.970043 & 29.602345 & \\
\hline 135 & & 2014 & 3418.383439 & -1.973088 & 29.592634 & \\
\hline 136 & & 2014 & 302.245021 & -1.969709 & 29.591746 & \\
\hline 137 & & 2014 & 1127.441854 & -1.969826 & 29.584354 & \\
\hline 138 & & 2014 & 500.374535 & -1.969039 & 29.584828 & \\
\hline 139 & & 2014 & 196.756307 & -1.97023 & 29.583747 & \\
\hline 140 & & 2014 & 254.831315 & -1.96897 & 29.58705 & \\
\hline 141 & & 2014 & 102.068382 & -1.961704 & 29.589933 & \\
\hline 142 & & 2014 & 94.328078 & -1.961785 & 29.589517 & \\
\hline 143 & & 2014 & 77.235774 & -1.960148 & 29.58752 & \\
\hline 144 & & 2015 & 58.994851 & -1.973214 & 29.573503 & \\
\hline 145 & & 2015 & 38.088711 & -1.973013 & 29.573021 & \\
\hline 146 & & 2015 & 311.305763 & -1.972987 & 29.572761 & \\
\hline 146 & & 2015 & 159.173148 & -1.973601 & 29.573527 & \\
\hline 147 & & 2015 & 75.858663 & -1.973473 & 29.572954 & \\
\hline 148 & & 2015 & 278.871881 & -1.973071 & 29.574211 & \\
\hline 149 & & 2015 & 39.717911 & -1.972997 & 29.574483 & \\
\hline 150 & & 2015 & 24.219851 & -1.973964 & 29.574352 & \\
\hline 151 & & 2015 & 367.073588 & -1.974176 & 29.560112 & \\
\hline 152 & & 2015 & 17556.65862 & -1.970569 & 29.571383 & \\
\hline 153 & & 2015 & 2421.225191 & -1.971306 & 29.571958 & \\
\hline 154 & & 2015 & 1116.691313 & -1.969731 & 29.572507 & \\
\hline 155 & & 2015 & 535.684134 & -1.961405 & 29.564043 & \\
\hline 156 & & 2015 & 1379.988312 & -1.960294 & 29.559823 & \\
\hline 157 & & & 3835.550238 & -1.966124 & 29.563321 & \\
\hline 158 & & 2015 & 164.353425 & -1.970446 & 29.577743 & \\
\hline 159 & & 2015 & 1103.687889 & -1.965997 & 29.56153 & \\
\hline 160 & & 2015 & 416.12872 & -1.965552 & 29.561771 & \\
\hline 161 & & 2014 & 106.31558 & -1.965132 & 29.562204 & \\
\hline 162 & & 2014 & 55.332253 & -1.965052 & 29.562269 & \\
\hline 163 & & 2015 & 140.477296 & -1.97261 & 29.561389 & \\
\hline 164 & & 2011 & 464.6711 & -1.968434 & 29.573069 & \\
\hline 165 & & 2015 & 3237.485948 & -1.968694 & 29.572547 & \\
\hline 166 & & 2014 & 104.614529 & -1.973731 & 29.576443 & \\
\hline 167 & & 2015 & 266.125595 & -1.969981 & 29.558052 & \\
\hline 168 & & 2014 & 1063.445038 & -1.95709 & 29.556319 & \\
\hline 169 & & 2015 & 380.510031 & -1.960515 & 29.553468 & \\
\hline 170 & & 2015 & 3913.923582 & -1.960605 & 29.549378 & \\
\hline 171 & & 2015 & 10853.81551 & -1.959665 & 29.547435 & \\
\hline 172 & & 2015 & 345.17444 & -1.966785 & 29.54486 & \\
\hline 173 & & 2014 & 318.261618 & -1.972543 & 29.544234 & \\
\hline 174 & & 2014 & 202.295597 & -1.96859 & 29.629105 & \\
\hline 175 & & 2014 & 517.040137 & -1.961937 & 29.614611 & \\
\hline 176 & & 2014 & 3693.617387 & -1.950651 & 29.629595 & \\
\hline 177 & & 2014 & 804.488433 & -1.951992 & 29.630107 & \\
\hline 178 & & 2014 & 2643.375677 & -1.94813 & 29.630305 & \\
\hline
\end{tabular}


2016 Focused Study (Precipitation) Landslide Inventory

\begin{tabular}{|c|c|c|c|c|c|}
\hline Name & Landslide Date & Area & $\begin{array}{l}\text { Latitude (in decimal } \\
\text { degrees) }\end{array}$ & $\begin{array}{l}\text { Longitude (in decimal } \\
\text { degrees) }\end{array}$ & Notes \\
\hline 179 & 2014 & 1118.563813 & -1.947189 & 29.629646 & \\
\hline 180 & 2014 & 424.218704 & -1.945318 & 29.628429 & \\
\hline 181 & 2014 & 1842.7764 & -1.942029 & 29.629555 & \\
\hline 182 & 2014 & 1022.794403 & -1.943939 & 29.623732 & \\
\hline 183 & 2014 & 2657.469544 & -1.944103 & 29.623343 & \\
\hline 184 & 2014 & 3181.018412 & -1.939789 & 29.619363 & \\
\hline 185 & 2014 & 331.333423 & -1.952423 & 29.629762 & \\
\hline 186 & 2014 & 34.578089 & -1.950882 & 29.630771 & \\
\hline 187 & 2014 & 7901.20508 & -1.951228 & 29.631299 & \\
\hline 188 & 2014 & 1461.951946 & -1.948603 & 29.629795 & \\
\hline 189 & 2014 & 1924.640936 & -1.949052 & 29.629212 & \\
\hline 190 & 2014 & 766.391059 & -1.949368 & 29.629897 & \\
\hline 191 & 2014 & 466.288782 & -1.95009 & 29.629719 & \\
\hline 192 & 2014 & 1538.396146 & -1.947552 & 29.631556 & \\
\hline 193 & 2014 & 652.634989 & -1.951171 & 29.630044 & \\
\hline 194 & 2014 & 21028.34379 & -1.934442 & 29.619138 & \\
\hline 195 & 2014 & 125525.4435 & -1.931336 & 29.615723 & \\
\hline 196 & 2014 & 15004.10663 & -1.936787 & 29.615972 & \\
\hline 197 & 2014 & 2228.512631 & -1.937466 & 29.615378 & \\
\hline 198 & 2014 & 425.642936 & -1.931918 & 29.626058 & \\
\hline 199 & 2014 & 380.518819 & -1.930748 & 29.626451 & \\
\hline 200 & 2014 & 14631.8474 & -1.9231 & 29.61764 & \\
\hline 201 & 2014 & 6598.713412 & -1.927926 & 29.61345 & \\
\hline 202 & 2014 & 3926.978541 & -1.927181 & 29.624886 & \\
\hline 203 & 2014 & 3045.763948 & -1.930933 & 29.611428 & \\
\hline 204 & 2014 & 23051.82421 & -1.928799 & 29.611941 & \\
\hline 205 & 2014 & 19984.17262 & -1.928449 & 29.605938 & \\
\hline 206 & 2014 & 511.326528 & -1.92608 & 29.605865 & \\
\hline 207 & 2014 & 5839.381044 & -1.926893 & 29.605043 & \\
\hline 208 & 2014 & 357.686759 & -1.9276 & 29.60337 & \\
\hline 209 & 2014 & 397.970054 & -1.934871 & 29.601179 & \\
\hline 210 & 2014 & 169.029695 & -1.934751 & 29.601885 & \\
\hline 211 & 2014 & 2433.254153 & -1.929898 & 29.607507 & \\
\hline 212 & 2014 & 125.508961 & -1.939213 & 29.602976 & \\
\hline 213 & 2014 & 189.46336 & -1.946405 & 29.599424 & \\
\hline 214 & 2014 & 333.904189 & -1.949338 & 29.61025 & \\
\hline 215 & 2014 & 345.351893 & -1.948329 & 29.611715 & \\
\hline 216 & 2014 & 1360.284355 & -1.952226 & 29.591595 & \\
\hline 217 & 2014 & 182.532463 & -1.952554 & 29.592902 & \\
\hline 218 & 2014 & 129.748988 & -1.952071 & 29.593078 & \\
\hline 219 & 2014 & 68.376285 & -1.95348 & 29.594979 & \\
\hline 220 & 2014 & 52.31525 & -1.954334 & 29.594641 & \\
\hline 221 & 2014 & 408.767932 & -1.953513 & 29.58303 & \\
\hline 222 & 2014 & 967.084138 & -1.944887 & 29.580053 & \\
\hline 223 & 2014 & 249.818388 & -1.945 & 29.579721 & \\
\hline 224 & 2014 & 287.728802 & -1.94416 & 29.579256 & \\
\hline 225 & 2015 & 244.184012 & -1.948218 & 29.554231 & \\
\hline 226 & 2015 & 148.241621 & -1.948423 & 29.55486 & \\
\hline 227 & 2015 & 278.531882 & -1.948247 & 29.554592 & \\
\hline 228 & 2015 & 254.427562 & -1.949253 & 29.55396 & \\
\hline 229 & 2015 & 104.358936 & -1.950525 & 29.548874 & \\
\hline 230 & 2015 & 248.714336 & -1.94959 & 29.548698 & \\
\hline 231 & 2015 & 206.972095 & -1.941106 & 29.553324 & \\
\hline 232 & 2015 & 117.504318 & -1.94004 & 29.549636 & \\
\hline 233 & 2015 & 285.230034 & -1.954609 & 29.558323 & \\
\hline 234 & 2014 & 165.762635 & -1.921788 & 29.595688 & \\
\hline 235 & 2014 & 118.251375 & -1.92172 & 29.586809 & \\
\hline 236 & 2014 & 1649.76438 & -1.922256 & 29.581737 & \\
\hline 237 & 2014 & 230.322939 & -1.923687 & 29.588591 & \\
\hline 238 & 2015 & 1785.415614 & -1.926219 & 29.556624 & \\
\hline
\end{tabular}


2016 Focused Study (Precipitation) Landslide Inventory

\begin{tabular}{|c|c|c|c|c|c|}
\hline Name & Landslide Date & Area & $\begin{array}{l}\text { Latitude (in decimal } \\
\text { degrees) }\end{array}$ & $\begin{array}{l}\text { Longitude (in decimal } \\
\text { degrees) }\end{array}$ & Notes \\
\hline 239 & 2015 & 243.854758 & -1.934618 & 29.550806 & \\
\hline 240 & 2015 & 2257.907811 & -1.926135 & 29.545565 & \\
\hline 241 & 2014 & 499.160516 & -1.927891 & 29.544089 & \\
\hline 242 & 2015 & 551.937905 & -1.952436 & 29.534598 & \\
\hline 243 & 2015 & 258.406974 & -1.945501 & 29.532606 & \\
\hline 244 & 2015 & 205.043275 & -1.94507 & 29.532587 & \\
\hline 245 & 2015 & 182.13322 & -1.941302 & 29.527643 & \\
\hline 246 & 2015 & 170.735336 & -1.941448 & 29.527199 & \\
\hline 247 & 2015 & 524.150682 & -1.943583 & 29.531268 & \\
\hline 248 & 2015 & 782.811801 & -1.943409 & 29.531906 & \\
\hline 249 & 2015 & 473.523064 & -1.958725 & 29.536872 & \\
\hline 250 & 2006 & 939.678098 & -1.967937 & 29.52956 & \\
\hline 251 & 2015 & 342.923118 & -1.987427 & 29.526731 & \\
\hline 252 & 2015 & 1596.24338 & -1.988968 & 29.524876 & \\
\hline 253 & 2015 & 315.817866 & -1.989449 & 29.52448 & \\
\hline 254 & 2015 & 2800.993294 & -1.990338 & 29.527267 & \\
\hline 255 & 2014 & 1120.871876 & -2.000898 & 29.524492 & \\
\hline 256 & 2014 & 312.803742 & -2.000767 & 29.52973 & \\
\hline 257 & 2014 & 1305.665583 & -2.00358 & 29.531188 & \\
\hline 258 & 2014 & 2144.177686 & -1.996912 & 29.516948 & \\
\hline 259 & 2014 & 1109.364765 & -1.995266 & 29.516117 & \\
\hline 260 & 2014 & 1317.46621 & -1.994995 & 29.515512 & \\
\hline 261 & 2014 & 925.05476 & -1.995231 & 29.514696 & \\
\hline 262 & 2014 & 156.320653 & -1.994945 & 29.514546 & \\
\hline 263 & 2014 & 88.887598 & -1.994709 & 29.514107 & \\
\hline 264 & 2014 & 133.705865 & -1.994554 & 29.513946 & \\
\hline 265 & 2014 & 198.708423 & -1.995111 & 29.519441 & \\
\hline 266 & 2014 & 444.213186 & -1.994776 & 29.519075 & \\
\hline 267 & 2014 & 277.028711 & -1.977531 & 29.506472 & \\
\hline 268 & 2014 & 371.544646 & -1.977497 & 29.507078 & \\
\hline 269 & 2014 & 3248.663068 & -1.978027 & 29.507219 & \\
\hline 270 & 2014 & 156.307791 & -1.978611 & 29.5077 & \\
\hline 271 & 2014 & 108.757982 & -1.977598 & 29.507411 & \\
\hline 272 & 2014 & 371.635227 & -1.977372 & 29.507421 & \\
\hline 273 & 2014 & 226.740514 & -1.982353 & 29.518871 & \\
\hline 274 & 2014 & 486.01856 & -1.982423 & 29.518186 & \\
\hline 275 & 2015 & 158.592207 & -1.981476 & 29.518222 & \\
\hline 276 & 2015 & 292.822712 & -1.981315 & 29.517969 & \\
\hline 276 & 2014 & 298.855258 & -1.987775 & 29.515794 & \\
\hline 277 & 2014 & 782.09506 & -1.987548 & 29.515358 & \\
\hline 278 & 2006 & 1165.994316 & -1.993158 & 29.515035 & \\
\hline 279 & 2015 & 840.733078 & -1.99255 & 29.514008 & \\
\hline 280 & 2006 & 1614.474759 & -1.992125 & 29.513653 & \\
\hline 281 & 2014 & 1492.704673 & -1.974994 & 29.514576 & \\
\hline 282 & 2014 & 712.679054 & -1.975226 & 29.512767 & \\
\hline 283 & 2014 & 446.738436 & -1.975388 & 29.512483 & \\
\hline 284 & 2014 & 535.3022 & -1.975174 & 29.51193 & \\
\hline 285 & 2006 & 1354.308259 & -1.974861 & 29.511847 & \\
\hline 286 & 2014 & 1544.899104 & -1.974948 & 29.509642 & \\
\hline 287 & 2014 & 610.245315 & -1.97407 & 29.508123 & \\
\hline 288 & 2014 & 990.484549 & -1.973644 & 29.509062 & \\
\hline 289 & 2014 & 368.068548 & -1.973511 & 29.509984 & \\
\hline 290 & 2014 & 271.599729 & -1.973971 & 29.509973 & \\
\hline 291 & 2006 & 208.668999 & -1.973198 & 29.50928 & \\
\hline 292 & 2006 & 1625.122674 & -1.972498 & 29.507918 & \\
\hline 293 & 2014 & 174.852604 & -1.956254 & 29.508804 & \\
\hline 294 & 2014 & 38.194644 & -1.956033 & 29.50873 & \\
\hline 295 & 2015 & 201.360646 & -1.956442 & 29.508848 & \\
\hline 296 & 2014 & 1091.533215 & -1.955917 & 29.522273 & \\
\hline 297 & 2014 & 359.47004 & -1.952527 & 29.523998 & \\
\hline
\end{tabular}


2016 Focused Study (Precipitation) Landslide Inventory

\begin{tabular}{|c|c|c|c|c|c|}
\hline Name & Landslide Date & Area & $\begin{array}{l}\text { Latitude (in decimal } \\
\text { degrees) }\end{array}$ & $\begin{array}{l}\text { Longitude (in decimal } \\
\text { degrees) }\end{array}$ & Notes \\
\hline 298 & 2014 & 807.775875 & -1.951494 & 29.524747 & \\
\hline 299 & 2015 & 284.340715 & -1.950265 & 29.529878 & \\
\hline 300 & 2015 & 593.272852 & -1.950898 & 29.521911 & \\
\hline 301 & 2015 & 688.134189 & -1.946967 & 29.51573 & \\
\hline 302 & 2014 & 4702.033219 & -1.947106 & 29.518861 & \\
\hline 303 & 2014 & 965.062276 & -1.947995 & 29.521357 & \\
\hline 304 & 2015 & 481.803568 & -1.945251 & 29.519911 & \\
\hline 305 & 2014 & 604.008676 & -1.941024 & 29.516105 & \\
\hline 306 & 2014 & 423.369136 & -1.939286 & 29.513797 & \\
\hline 307 & 2014 & 119.027206 & -1.940154 & 29.513697 & \\
\hline 308 & 2015 & 169.704348 & -1.941981 & 29.513231 & \\
\hline 309 & 2014 & 574.551038 & -1.946019 & 29.511029 & \\
\hline 310 & 2015 & 90.34752 & -1.945423 & 29.508397 & \\
\hline 311 & 2014 & 1138.659359 & -1.950003 & 29.504973 & \\
\hline 312 & 2014 & 170.153083 & -1.941455 & 29.501659 & \\
\hline 313 & 2014 & 95.03419 & -1.940461 & 29.499585 & \\
\hline 314 & 2014 & 112.660962 & -1.940462 & 29.499779 & \\
\hline 315 & 2015 & 282.843239 & -1.954947 & 29.519042 & \\
\hline 316 & 2014 & 137.145975 & -1.954741 & 29.518534 & \\
\hline 317 & 2014 & 55.808413 & -1.954884 & 29.518239 & \\
\hline 318 & 2015 & 40.496312 & -1.953058 & 29.518955 & \\
\hline 319 & 2015 & 114.876181 & -1.95273 & 29.507441 & \\
\hline 320 & 2015 & 396.037439 & -1.944562 & 29.523158 & \\
\hline 321 & 2015 & 1515.53947 & -1.948938 & 29.524178 & \\
\hline 322 & 2015 & 115.186639 & -1.945647 & 29.521938 & \\
\hline 323 & 2015 & 513.126371 & -1.950646 & 29.512695 & \\
\hline 324 & 2014 & 54.809759 & -1.933638 & 29.506889 & \\
\hline 325 & 2014 & 265.043407 & -1.921982 & 29.506905 & \\
\hline 326 & 2015 & 87.926748 & -1.916229 & 29.517438 & \\
\hline 327 & 2015 & 2898.859638 & -1.903754 & 29.51096 & \\
\hline 328 & 2014 & 1285.73258 & -1.90955 & 29.53974 & \\
\hline 329 & 2014 & 1108.283365 & -1.910358 & 29.53303 & \\
\hline 330 & 2014 & 844.492147 & -1.909544 & 29.532766 & \\
\hline 331 & 2014 & 108.906184 & -1.908058 & 29.557454 & \\
\hline 332 & 2014 & 50.499126 & -1.908137 & 29.557502 & \\
\hline 333 & 2015 & 421.77205 & -1.915725 & 29.55803 & \\
\hline 334 & 2014 & 2438.971643 & -1.915908 & 29.543283 & \\
\hline 335 & 2006 & 139.430865 & -1.918637 & 29.548691 & \\
\hline 336 & 2015 & 5847.317924 & -1.907589 & 29.564386 & \\
\hline 337 & 2014 & 1720.099349 & -1.908447 & 29.58803 & \\
\hline 338 & 2014 & 2079.347611 & -1.910427 & 29.588064 & \\
\hline 339 & 2014 & 2092.646166 & -1.904094 & 29.589933 & \\
\hline 340 & 2006 & 292.754561 & -1.91211 & 29.598197 & \\
\hline 341 & 2014 & 360.988139 & -1.912462 & 29.597937 & \\
\hline 342 & 2014 & 254.347327 & -1.912699 & 29.597234 & \\
\hline 343 & 2014 & 92.297222 & -1.912723 & 29.597603 & \\
\hline 344 & 2014 & 845.103275 & -1.912696 & 29.598716 & \\
\hline 345 & 2014 & 157.043368 & -1.912357 & 29.597173 & \\
\hline 346 & 2014 & 726.93186 & -1.910533 & 29.605509 & \\
\hline 347 & 2014 & 110.900706 & -1.910124 & 29.606053 & \\
\hline 348 & 2014 & 567.826694 & -1.909363 & 29.610294 & \\
\hline 349 & 2014 & 287.082633 & -1.907321 & 29.608687 & \\
\hline 350 & 2014 & 171.4943 & -1.907184 & 29.608164 & \\
\hline 351 & 2014 & 9358.722503 & -1.909257 & 29.612437 & \\
\hline 352 & 2014 & 248.39119 & -1.916356 & 29.598951 & \\
\hline 353 & 2014 & 711.939427 & -1.919073 & 29.628087 & \\
\hline 354 & 2014 & 127.289109 & -1.918823 & 29.623906 & \\
\hline 355 & 2014 & 215.484968 & -1.915641 & 29.623776 & \\
\hline 356 & 2014 & 1736.152369 & -1.896607 & 29.629881 & \\
\hline 357 & 2014 & 194.656492 & -1.898529 & 29.630264 & \\
\hline
\end{tabular}


2016 Focused Study (Precipitation) Landslide Inventory

\begin{tabular}{|c|c|c|c|c|c|}
\hline Name & Landslide Date & Area & $\begin{array}{l}\text { Latitude (in decimal } \\
\text { degrees) }\end{array}$ & $\begin{array}{l}\text { Longitude (in decimal } \\
\text { degrees) }\end{array}$ & Notes \\
\hline 358 & 2014 & 891.831565 & -1.892633 & 29.598267 & \\
\hline 359 & 2014 & 427.670762 & -1.89275 & 29.598507 & \\
\hline 360 & 2014 & 322.265483 & -1.893112 & 29.598922 & \\
\hline 361 & 2014 & 877.70554 & -1.899538 & 29.601901 & \\
\hline 362 & 2014 & 724.505063 & -1.892888 & 29.596084 & \\
\hline 363 & 2014 & 349.621675 & -1.900553 & 29.60551 & \\
\hline 364 & 2014 & 2701.285797 & -1.885494 & 29.585233 & \\
\hline 365 & 2014 & 13157.98815 & -1.890537 & 29.583749 & \\
\hline 366 & 2014 & 7629.94107 & -1.89398 & 29.581136 & \\
\hline 367 & 2014 & 683.543256 & -1.90116 & 29.593078 & \\
\hline 368 & 2014 & 116.230487 & -1.894832 & 29.568979 & \\
\hline 369 & 2015 & 89.713512 & -1.894417 & 29.559893 & \\
\hline 370 & 2014 & 114.344333 & -1.893437 & 29.529181 & \\
\hline 371 & 2015 & 2317.848798 & -1.888208 & 29.527387 & \\
\hline 372 & 2014 & 538.903801 & -1.887614 & 29.526041 & \\
\hline 373 & 2015 & 174.845637 & -1.898993 & 29.533606 & \\
\hline 374 & 2014 & 359.903716 & -1.900134 & 29.535062 & \\
\hline 375 & 2015 & 122.40605 & -1.902586 & 29.507592 & \\
\hline 376 & 2015 & 215.643385 & -1.902456 & 29.507244 & \\
\hline 377 & 2015 & 165.635064 & -1.902152 & 29.507169 & \\
\hline 378 & 2015 & 106.241964 & -1.897648 & 29.506474 & \\
\hline 378 & 2015 & 1463.69568 & -1.890978 & 29.512346 & \\
\hline 379 & 2015 & 41.502687 & -1.890949 & 29.512765 & \\
\hline 380 & 2014 & 419.832423 & -1.889626 & 29.515106 & \\
\hline 381 & 2015 & 565.341566 & -1.888801 & 29.518614 & \\
\hline 382 & 2015 & 379.885579 & -1.895552 & 29.510133 & \\
\hline 383 & 2015 & 530.752764 & -1.895781 & 29.510564 & \\
\hline 384 & 2014 & 336.252382 & -1.879166 & 29.535074 & \\
\hline 385 & 2015 & 367.039425 & -1.8728 & 29.542599 & \\
\hline 386 & 2014 & 609.911775 & -1.867297 & 29.584917 & \\
\hline 387 & 2014 & 50.008089 & -1.871566 & 29.586527 & \\
\hline 388 & 2014 & 781.038305 & -1.875169 & 29.613213 & \\
\hline 389 & 2014 & 280.614571 & -1.881065 & 29.607464 & \\
\hline 390 & 2014 & 143.516204 & -1.877284 & 29.603322 & \\
\hline 391 & 2014 & 42.558231 & -1.877137 & 29.602823 & \\
\hline 392 & 2014 & 87.79735 & -1.868861 & 29.596485 & \\
\hline 393 & 2014 & 55.389816 & -1.869143 & 29.596487 & \\
\hline 394 & 2014 & 105.585181 & -1.869419 & 29.596715 & \\
\hline 395 & 2014 & 143.849072 & -1.86909 & 29.596598 & \\
\hline 396 & 2014 & 2566.356276 & -1.872642 & 29.615269 & \\
\hline 397 & 2015 & 820.336371 & -1.990827 & 29.506219 & \\
\hline 398 & 2015 & 1749.849445 & -1.990139 & 29.503133 & \\
\hline 399 & 2015 & 333.237376 & -1.991414 & 29.502135 & \\
\hline 400 & 2015 & 216.592556 & -1.984983 & 29.494863 & \\
\hline 401 & 2015 & 594.820668 & -1.97723 & 29.506106 & \\
\hline 402 & 2015 & 2951.542271 & -1.971109 & 29.506674 & \\
\hline 403 & 2014 & 207.367435 & -1.957539 & 29.498376 & \\
\hline 404 & 2014 & 238.831829 & -1.957791 & 29.498656 & \\
\hline 405 & 2014 & 147.572247 & -1.966292 & 29.500551 & \\
\hline 406 & 2014 & 200.794296 & -1.966459 & 29.501024 & \\
\hline 407 & 2014 & 121.893212 & -1.966607 & 29.501248 & \\
\hline 408 & 2014 & 193.591 & -1.968292 & 29.502726 & \\
\hline 409 & 2014 & 77.136877 & -1.968058 & 29.502284 & \\
\hline 410 & 2015 & 73.242702 & -1.936347 & 29.496153 & \\
\hline 411 & 2015 & 96.254186 & -1.934071 & 29.49078 & \\
\hline 412 & 2015 & 1990.538464 & -1.931289 & 29.490978 & \\
\hline 413 & 2015 & 168.099047 & -1.930644 & 29.490462 & \\
\hline 414 & 2015 & 245.239023 & -1.928386 & 29.495892 & \\
\hline 415 & 2015 & 1148.071866 & -1.927984 & 29.495331 & \\
\hline 416 & 2015 & 4736.044284 & -1.926951 & 29.494101 & \\
\hline
\end{tabular}


2016 Focused Study (Precipitation) Landslide Inventory

\begin{tabular}{|c|c|c|c|c|c|}
\hline Name & Landslide Date & Area & $\begin{array}{l}\text { Latitude (in decimal } \\
\text { degrees) }\end{array}$ & $\begin{array}{l}\text { Longitude (in decimal } \\
\text { degrees) }\end{array}$ & Notes \\
\hline 417 & 2015 & 1765.85269 & -1.919157 & 29.499617 & \\
\hline 418 & 2015 & 467.804534 & -1.918275 & 29.497472 & \\
\hline 419 & 2015 & 5586.12759 & -1.916138 & 29.497619 & \\
\hline 420 & 2015 & 1621.480381 & -1.917278 & 29.498329 & \\
\hline 421 & 2015 & 385.494949 & -1.914453 & 29.493098 & \\
\hline 422 & 2015 & 2269.713708 & -1.911503 & 29.48837 & \\
\hline 423 & 2015 & 306.117243 & -1.918402 & 29.493118 & \\
\hline 424 & 2015 & 147.344242 & -1.894606 & 29.492597 & \\
\hline 425 & 2015 & 802.553162 & -1.888142 & 29.490927 & \\
\hline 426 & 2015 & 764.899185 & -1.88771 & 29.489272 & \\
\hline 427 & 2015 & 746.353758 & -1.892983 & 29.501652 & \\
\hline 428 & 2015 & 208.580582 & -1.891204 & 29.502129 & \\
\hline 429 & 2015 & 135.189913 & -1.896735 & 29.503863 & \\
\hline 430 & 2015 & 638.776761 & -1.88792 & 29.487177 & \\
\hline 431 & 2015 & 182.342672 & -1.886324 & 29.487947 & \\
\hline 432 & 2015 & 85.915889 & -1.886015 & 29.487939 & \\
\hline 433 & 2015 & 754.364529 & -1.8852 & 29.480113 & \\
\hline 434 & 2015 & 132.010453 & -1.889547 & 29.480352 & \\
\hline 435 & 2015 & 89.42936 & -1.890457 & 29.474453 & \\
\hline 436 & 2015 & 31.34196 & -1.891261 & 29.474237 & \\
\hline 437 & 2015 & 117.340871 & -1.894747 & 29.473326 & \\
\hline 438 & 2015 & 245.172109 & -1.885451 & 29.470034 & \\
\hline 439 & 2015 & 281.703072 & -1.889273 & 29.459208 & \\
\hline 440 & 2015 & 57.064446 & -1.889041 & 29.459467 & \\
\hline 441 & 2015 & 46.725769 & -1.888888 & 29.459381 & \\
\hline 442 & 2015 & 29.72723 & -1.888746 & 29.459321 & \\
\hline 443 & 2015 & 116.337677 & -1.889944 & 29.461928 & \\
\hline 444 & 2015 & 93.119053 & -1.889716 & 29.461618 & \\
\hline 445 & 2015 & 68.870832 & -1.889762 & 29.461712 & \\
\hline 446 & 2015 & 383.547143 & -1.889883 & 29.460006 & \\
\hline 447 & 2006 & 965.01074 & -1.889335 & 29.460868 & \\
\hline 448 & 2006 & 11512.58635 & -1.894147 & 29.465826 & \\
\hline 449 & 2006 & 3526.092188 & -1.899689 & 29.463143 & \\
\hline 450 & 2006 & 2806.058886 & -1.899779 & 29.461831 & \\
\hline 451 & 2006 & 4290.374898 & -1.900733 & 29.466988 & \\
\hline 452 & 2015 & 553.620911 & -1.880371 & 29.496272 & \\
\hline 453 & 2015 & 1056.517822 & -1.870927 & 29.488209 & \\
\hline 454 & 2015 & 328.103274 & -1.884328 & 29.484148 & \\
\hline 455 & 2015 & 89.23789 & -1.881302 & 29.478415 & \\
\hline 456 & 2006 & 2268.833917 & -1.878172 & 29.470267 & \\
\hline 457 & 2015 & 10908.08468 & -1.879237 & 29.468219 & \\
\hline 458 & & 969.339479 & -1.879132 & 29.466636 & \\
\hline 459 & 2015 & 406.164568 & -1.878691 & 29.465836 & \\
\hline 460 & 2006 & 1899.703328 & -1.86818 & 29.46568 & \\
\hline 461 & 2015 & 1755.361673 & -1.874734 & 29.465087 & \\
\hline 462 & 2015 & 182.66606 & -1.875645 & 29.46372 & \\
\hline 463 & 2006 & 97.208271 & -1.880229 & 29.464541 & \\
\hline 464 & 2006 & 52.838546 & -1.879878 & 29.464619 & \\
\hline 455 & 2015 & 308.250798 & -1.879228 & 29.463662 & \\
\hline 456 & 2015 & 400.306376 & -1.880013 & 29.463785 & \\
\hline 457 & 2015 & 956.907763 & -1.880222 & 29.463397 & \\
\hline 458 & 2015 & 247.586999 & -1.880663 & 29.462971 & \\
\hline 459 & 2015 & 535.386541 & -1.880003 & 29.465258 & \\
\hline 460 & 2015 & 223.342581 & -1.881535 & 29.465368 & \\
\hline 461 & 2015 & 7965.463437 & -1.873574 & 29.462631 & \\
\hline 462 & 2015 & 3190.901347 & -1.873323 & 29.461242 & \\
\hline 463 & 2015 & 2281.212578 & -1.874818 & 29.461161 & \\
\hline 464 & 2015 & 160.300772 & -1.874427 & 29.460666 & \\
\hline 456 & 2006 & 1448.28768 & -1.870364 & 29.457179 & \\
\hline 457 & 2006 & 346.186182 & -1.87015 & 29.45778 & \\
\hline
\end{tabular}


2016 Focused Study (Precipitation) Landslide Inventory

\begin{tabular}{|c|c|c|c|c|c|}
\hline Name & Landslide Date & Area & $\begin{array}{l}\text { Latitude (in decimal } \\
\text { degrees) }\end{array}$ & $\begin{array}{l}\text { Longitude (in decimal } \\
\text { degrees) }\end{array}$ & Notes \\
\hline 458 & 2006 & 1758.080331 & -1.870012 & 29.456311 & \\
\hline 459 & 2006 & 62.176083 & -1.869817 & 29.455839 & \\
\hline 460 & 2006 & 74.410048 & -1.869749 & 29.455694 & \\
\hline 461 & 2015 & 224.623055 & -1.870017 & 29.453105 & \\
\hline 462 & 2015 & 879.837308 & -1.86961 & 29.45307 & \\
\hline 463 & 2015 & 216.870124 & -1.869523 & 29.453505 & \\
\hline 464 & 2015 & 4097.469286 & -1.869705 & 29.453958 & \\
\hline 465 & 2015 & 1784.050494 & -1.87169 & 29.453086 & \\
\hline 466 & 2015 & 987.742973 & -1.872696 & 29.455124 & \\
\hline 467 & 2015 & 1945.589627 & -1.873177 & 29.454426 & \\
\hline 468 & 2015 & 109.051551 & -1.874545 & 29.454372 & \\
\hline 469 & 2015 & 93.09637 & -1.87438 & 29.455275 & \\
\hline 470 & 2015 & 171.6392 & -1.874334 & 29.454978 & \\
\hline 471 & 2015 & 269.900105 & -1.874054 & 29.454315 & \\
\hline 472 & 2015 & 95.226877 & -1.874372 & 29.455479 & \\
\hline 473 & 2015 & 159.894253 & -1.874743 & 29.455151 & \\
\hline 474 & 2015 & 43.597108 & -1.874576 & 29.45564 & \\
\hline 475 & 2015 & 54.207238 & -1.874621 & 29.455708 & \\
\hline 476 & 2015 & 518.325813 & -1.87466 & 29.45553 & \\
\hline 477 & 2015 & 49.604476 & -1.875361 & 29.455682 & \\
\hline 478 & 2015 & 29.130368 & -1.875394 & 29.45579 & \\
\hline 479 & 2015 & 79.717982 & -1.875256 & 29.456002 & \\
\hline 480 & 2015 & 65.430726 & -1.875173 & 29.456228 & \\
\hline 481 & 2015 & 718.795155 & -1.874971 & 29.455995 & \\
\hline 482 & 2015 & 1519.843864 & -1.873793 & 29.45623 & \\
\hline 483 & 2015 & 847.622061 & -1.874001 & 29.456748 & \\
\hline 484 & 2015 & 1796.694833 & -1.874037 & 29.457221 & \\
\hline 485 & 2015 & 1998.247388 & -1.874391 & 29.457656 & \\
\hline 486 & 2015 & 207.613144 & -1.873967 & 29.457994 & \\
\hline 487 & 2015 & 79.567262 & -1.873698 & 29.457717 & \\
\hline 488 & 2015 & 45.262565 & -1.874082 & 29.458164 & \\
\hline 489 & 2015 & 890.635761 & -1.874092 & 29.458477 & \\
\hline 490 & 2015 & 623.710667 & -1.876314 & 29.457189 & \\
\hline 491 & 2015 & 273.950592 & -1.880205 & 29.462087 & \\
\hline 492 & 2015 & 680.460866 & -1.879717 & 29.452375 & \\
\hline 493 & 2015 & 222.836614 & -1.880036 & 29.4533 & \\
\hline 494 & 2015 & 1130.951733 & -1.869662 & 29.455266 & \\
\hline 495 & 2015 & 78.720729 & -1.869696 & 29.456656 & \\
\hline 496 & 2015 & 78.191034 & -1.879407 & 29.460749 & \\
\hline 497 & 2015 & 84.139548 & -1.879639 & 29.460532 & \\
\hline 498 & 2015 & 165.447342 & -1.879894 & 29.460503 & \\
\hline 499 & 2015 & 271.676827 & -1.877926 & 29.465552 & \\
\hline 500 & 2015 & 532.314654 & -1.914668 & 29.46315 & \\
\hline 501 & 2015 & 3183.845921 & -1.916546 & 29.459128 & \\
\hline 502 & 2015 & 817.677557 & -1.915923 & 29.458599 & \\
\hline 503 & 2015 & 162.735653 & -1.910865 & 29.45397 & \\
\hline 504 & 2015 & 346.085043 & -1.905603 & 29.455978 & \\
\hline 506 & 2006 & 358.435142 & -1.903035 & 29.452508 & \\
\hline 505 & 2006 & 354.284385 & -1.903504 & 29.452609 & \\
\hline 507 & 2006 & 173.126528 & -1.902789 & 29.45283 & \\
\hline 508 & 2006 & 125.226984 & -1.902531 & 29.452275 & \\
\hline 509 & 2006 & 597.750947 & -1.901522 & 29.452406 & \\
\hline 510 & 2006 & 283.82975 & -1.906676 & 29.452531 & \\
\hline 511 & 2006 & 289.563795 & -1.903975 & 29.45258 & \\
\hline 512 & 2006 & 159.522504 & -1.904219 & 29.462995 & \\
\hline 513 & 2015 & 1104.560348 & -1.907902 & 29.462102 & \\
\hline 514 & 2015 & 107.815273 & -1.908466 & 29.462892 & \\
\hline 515 & 2015 & 338.480755 & -1.914066 & 29.478361 & \\
\hline 516 & 2015 & 600.87535 & -1.910991 & 29.478579 & \\
\hline 517 & 2015 & 764.121933 & -1.912224 & 29.486626 & \\
\hline
\end{tabular}


2016 Focused Study (Precipitation) Landslide Inventory

\begin{tabular}{|c|c|c|c|c|c|}
\hline Name & Landslide Date & Area & $\begin{array}{l}\text { Latitude (in decimal } \\
\text { degrees) }\end{array}$ & $\begin{array}{l}\text { Longitude (in decimal } \\
\text { degrees) }\end{array}$ & Notes \\
\hline 518 & 2015 & 173.842684 & -1.912211 & 29.486403 & \\
\hline 519 & 2015 & 250.235444 & -1.913183 & 29.48678 & \\
\hline 520 & 2015 & 484.711238 & -1.917118 & 29.485623 & \\
\hline 521 & 2015 & 625.884044 & -1.915029 & 29.471892 & \\
\hline 522 & 2015 & 113.467443 & -1.936665 & 29.488163 & \\
\hline 523 & 2015 & 129.942293 & -1.936543 & 29.487596 & \\
\hline 524 & 2006 & 2694.747294 & -1.952183 & 29.469232 & \\
\hline 525 & 2006 & 428.220184 & -1.952443 & 29.468887 & \\
\hline 526 & 2006 & 130.443876 & -1.952531 & 29.468681 & \\
\hline 527 & 2015 & 460.958203 & -1.951595 & 29.464215 & \\
\hline 528 & 2015 & 262.22194 & -1.942228 & 29.459777 & \\
\hline 529 & 2015 & 575.386025 & -1.942709 & 29.459973 & \\
\hline 530 & 2015 & 1062.135271 & -1.947214 & 29.454122 & \\
\hline 531 & 2015 & 206.200704 & -1.946211 & 29.452717 & \\
\hline 532 & 2015 & 639.626328 & -1.943205 & 29.454605 & \\
\hline 533 & 2015 & 827.618284 & -1.937926 & 29.475248 & \\
\hline 534 & 2015 & 164.034604 & -1.948217 & 29.477354 & \\
\hline 535 & 2015 & 191.700539 & -1.976255 & 29.469725 & \\
\hline 536 & 2014 & 88.902612 & -1.982612 & 29.472645 & \\
\hline 537 & 2015 & 100.508432 & -1.993319 & 29.476104 & \\
\hline 538 & 2015 & 200.959428 & -1.995372 & 29.488837 & \\
\hline 539 & 2015 & 320.154447 & -2.026337 & 29.488163 & \\
\hline 540 & 2015 & 243.415042 & -2.016513 & 29.482576 & \\
\hline 541 & 2015 & 74.218207 & -2.013842 & 29.477686 & \\
\hline 542 & 2015 & 158.467072 & -2.013965 & 29.452469 & \\
\hline 543 & 2015 & 271.865045 & -2.027519 & 29.457333 & \\
\hline 544 & 2015 & 141.868884 & -2.010715 & 29.46165 & \\
\hline 545 & 2015 & 96.687019 & -2.023274 & 29.468859 & \\
\hline 546 & 2015 & 590.450659 & -2.024863 & 29.467457 & \\
\hline 547 & 2015 & 222.12665 & -2.02965 & 29.45472 & \\
\hline 548 & 2015 & 423.082423 & -2.043355 & 29.477824 & \\
\hline 549 & 2015 & 463.065191 & -2.041049 & 29.481293 & \\
\hline 550 & 2015 & 1623.426622 & -2.041988 & 29.459399 & \\
\hline 551 & 2015 & 976.918585 & -2.043203 & 29.463938 & \\
\hline 552 & 2002 & 4345.625143 & -2.043205 & 29.463013 & \\
\hline 553 & 2002 & 1342.95527 & -2.043364 & 29.466003 & \\
\hline 554 & 2015 & 113.940091 & -2.042751 & 29.454663 & \\
\hline
\end{tabular}




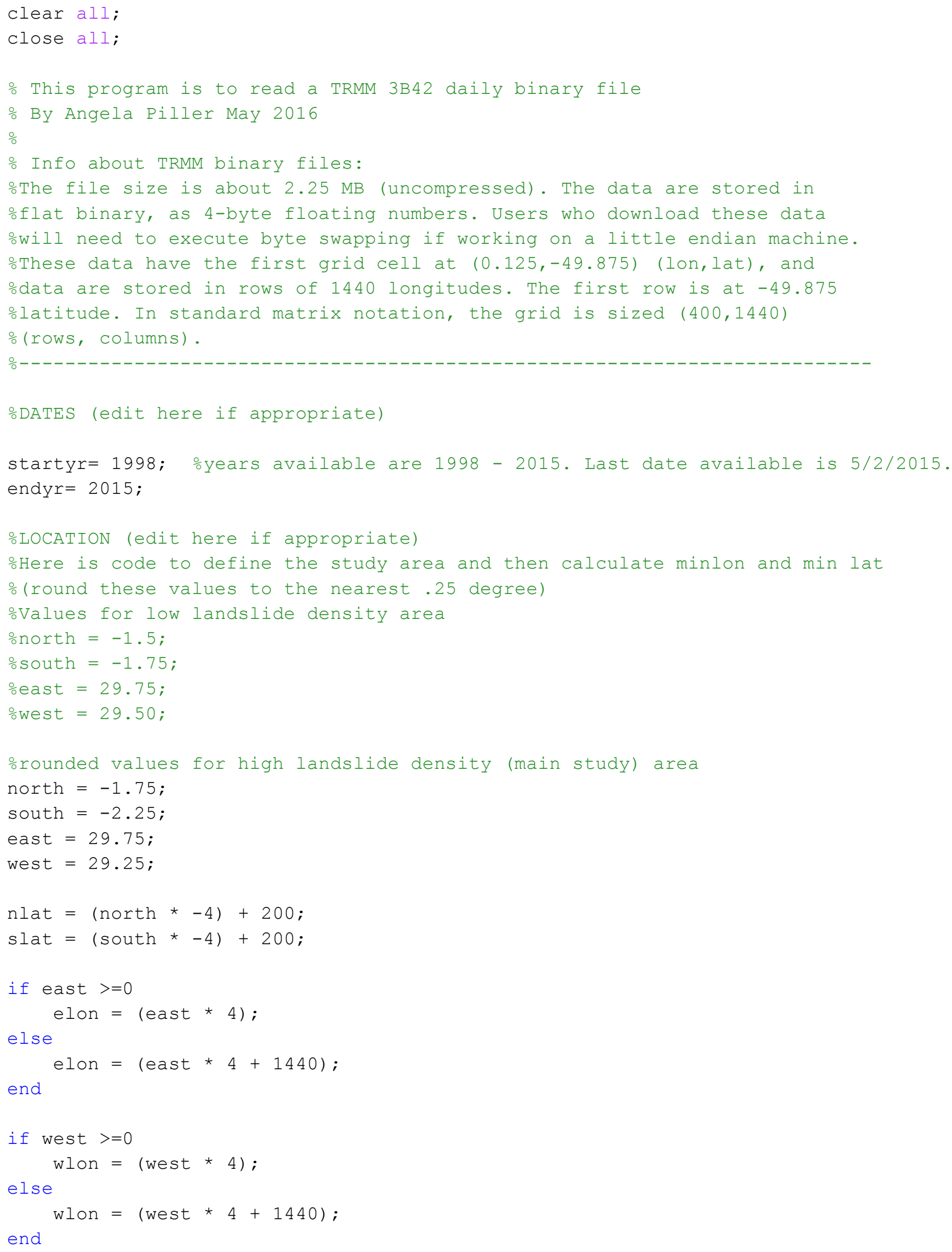




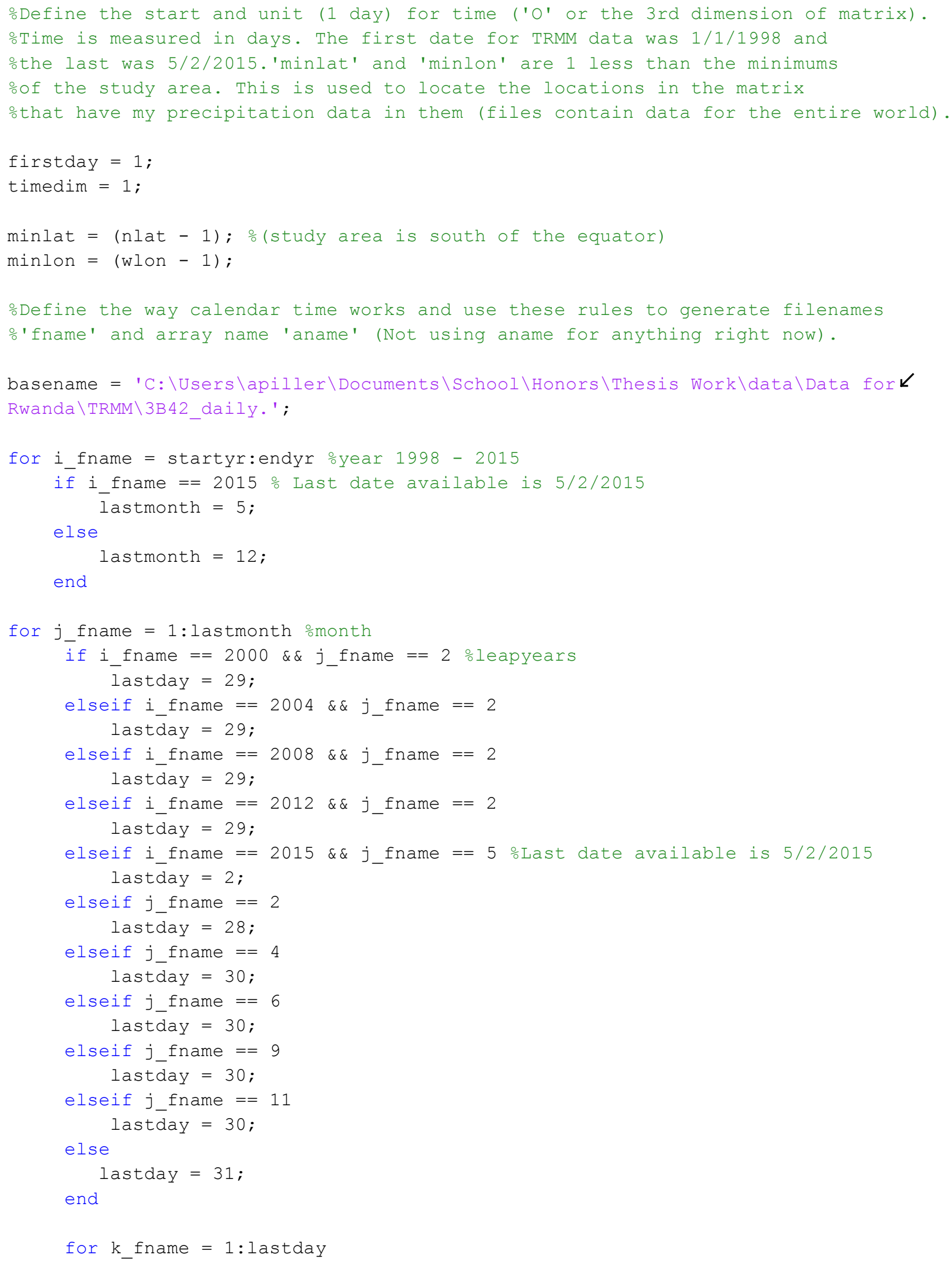




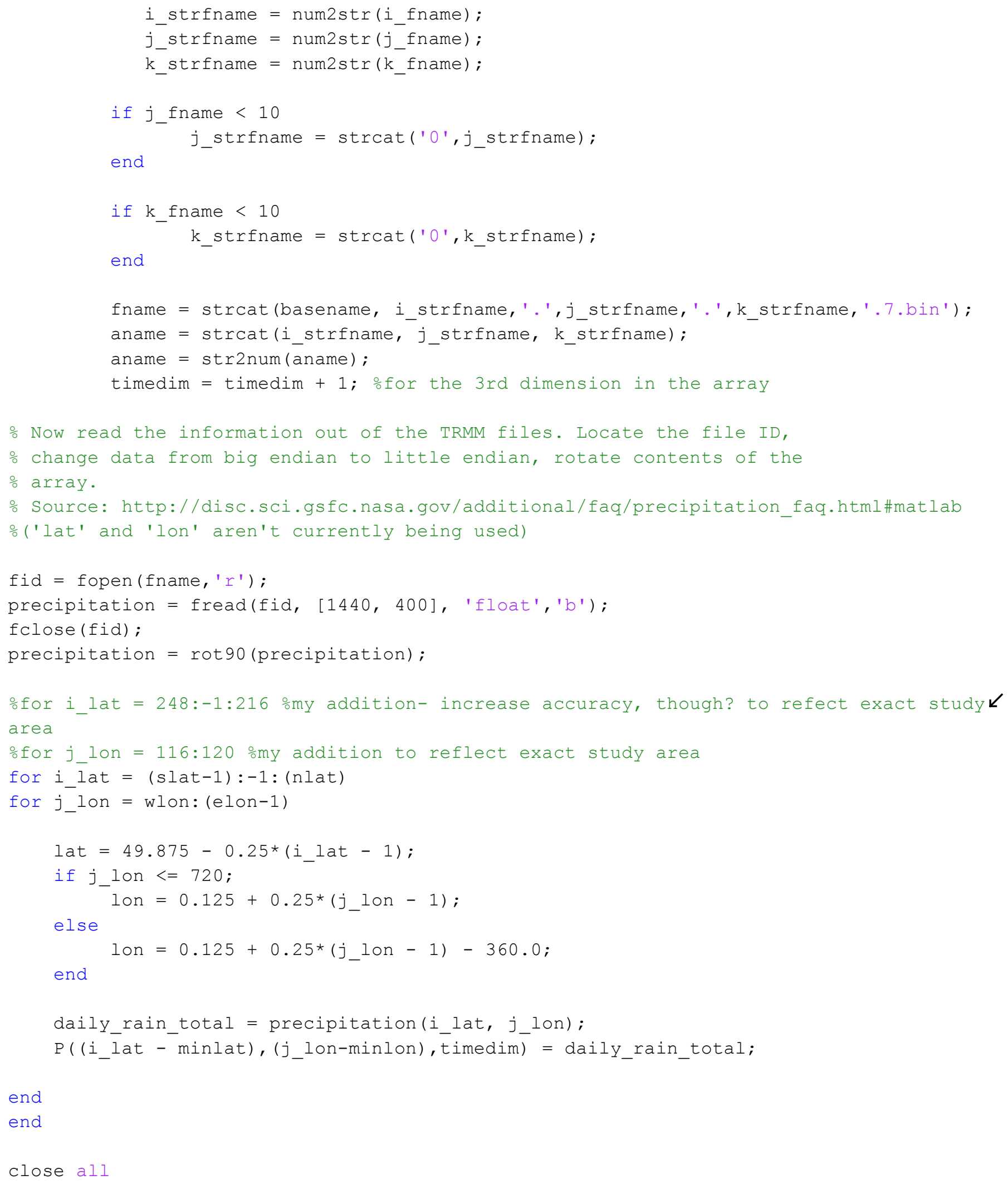




\section{end}

end

○ONLY FOR MAIN STUDY AREA COMMENT OUT AND USE LOW DENSITY VERSION

oAverage values for all four TRMM pixels together, put them in a new matrix.

\%Weight them 54\% North pixel, 19.5\% North2 pixel, 19.5\% South pixel, 7\%

ㅇouth2 pixel.

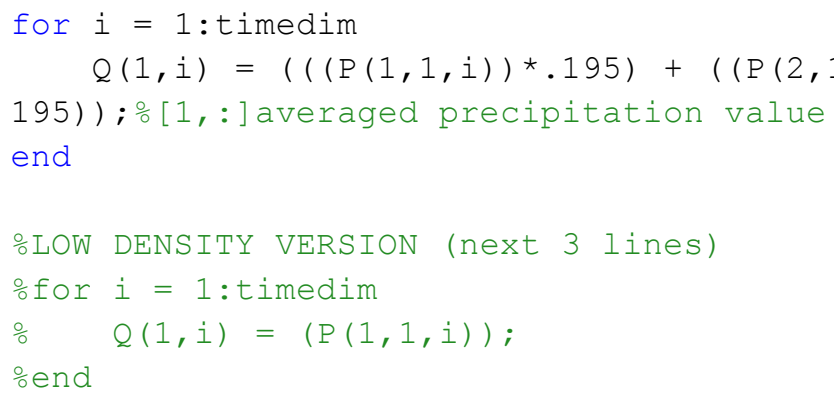




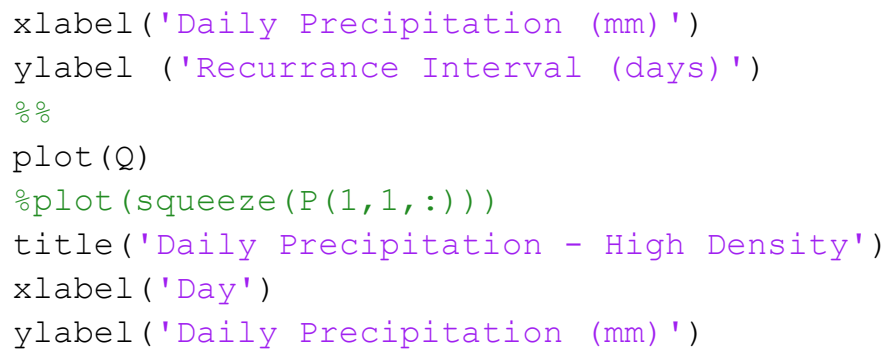

